Supplement of SOIL, 4, 259-266, 2018

https://doi.org/10.5194/soil-4-259-2018-supplement

(C) Author(s) 2018. This work is distributed under

the Creative Commons Attribution 4.0 License.

(c) (1)

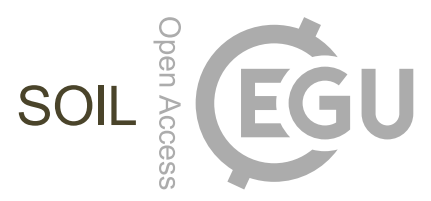

Supplement of

\title{
Spatial assessments of soil organic carbon for stakeholder decision-making - a case study from Kenya
}

Tor-Gunnar Vågen et al.

Correspondence to: Tor-Gunnar Vågen (t.vagen@cgiar.org)

The copyright of individual parts of the supplement might differ from the CC BY 4.0 License. 


\section{EVIDENCE INTO DECISION MAKING FOR RESILIENCE PLANNING IN TURKANA COUNTY}

\section{TURKANA COUNTY RESILIENCE DIAGNOSTIC AND DECISION SUPPORT TOOL}


Chesterman, S. \& Neely, C. 2015. Evidence into decision making for resilience planning in Turkana County: Stakeholder Approach for Risk Informed and Evidence Based Decision Making (SHARED). World Agroforestry Centre, Nairobi.

Edited by: Sabrina Chesterman \& Constance Neely

Contributing Chapter Co-Authors: T.Vagen,

Other Contributors: E. Namuar, V.Lekaram, P. Aemun, M. Limbu, M.Hassan, S.

Noormark and all other members of the Turkana SHARED Team from across the Institutions

Design and layout: Janine Petzer (Janine Petzer Illustration \& Design)

World Agroforestry Centre

PO Box 30677 - 00100

Nairobi

Kenya

Tel: +254207224000

Fax: +254207224001

Email: worldagroforestry@cgiar.org

Website: www.worldagroforestry.org

ISBN 978-92-9059-392.8

(c) ICRAF (2015)

The document is produced by ICRAF in collaboration with the Government of Turkana, UNICEF, the Millennium Institute and the National Drought Management Authority (NDMA) and is considered a Global Public Good. Users are invited to share, copy and distribute with acknowledgement of the sources.

Acknowledgement of Financial support:

The Turkana SHARED effort has been jointly funded through Technical Consortium for Building Resilience in the Horn of Africa by USAID as well as UNICEF and the World Agroforestry Centre. The authors and partners are grateful for this valuable support.

All images remain the sole property of their source and may not be used for any purpose without written permission of the source.

Views expressed in this publication are those of the authors and do not necessarily reflect the views of the World Agroforestry Centre.

The geographic designation employed and the presentation of material in this publication do not imply the expression of any opinion whatsoever on the part of the World Agroforestry Centre concerning the legal status of any country, territory, city or area or its authorities, or concerning the delimitation of its frontiers or boundaries. 


\section{TABLE OF CONTENTS}

1- Landing Page

2. Education

3- Security

4. Livestock

5- Land Health

6- Energy

7. Irrigation

8- Health

9. Water, Sanitation and Hygiene

10 Nutrition

11. Moving forward with the tool 


\section{RESILIENCE DIAGNOSTIC AND DECISION SUPPORT TOOL MANUAL}

\section{RESILIENCE DIAGNOSTIC ${ }^{\circ}$ \& DECISION SUPPORT TOOL .}

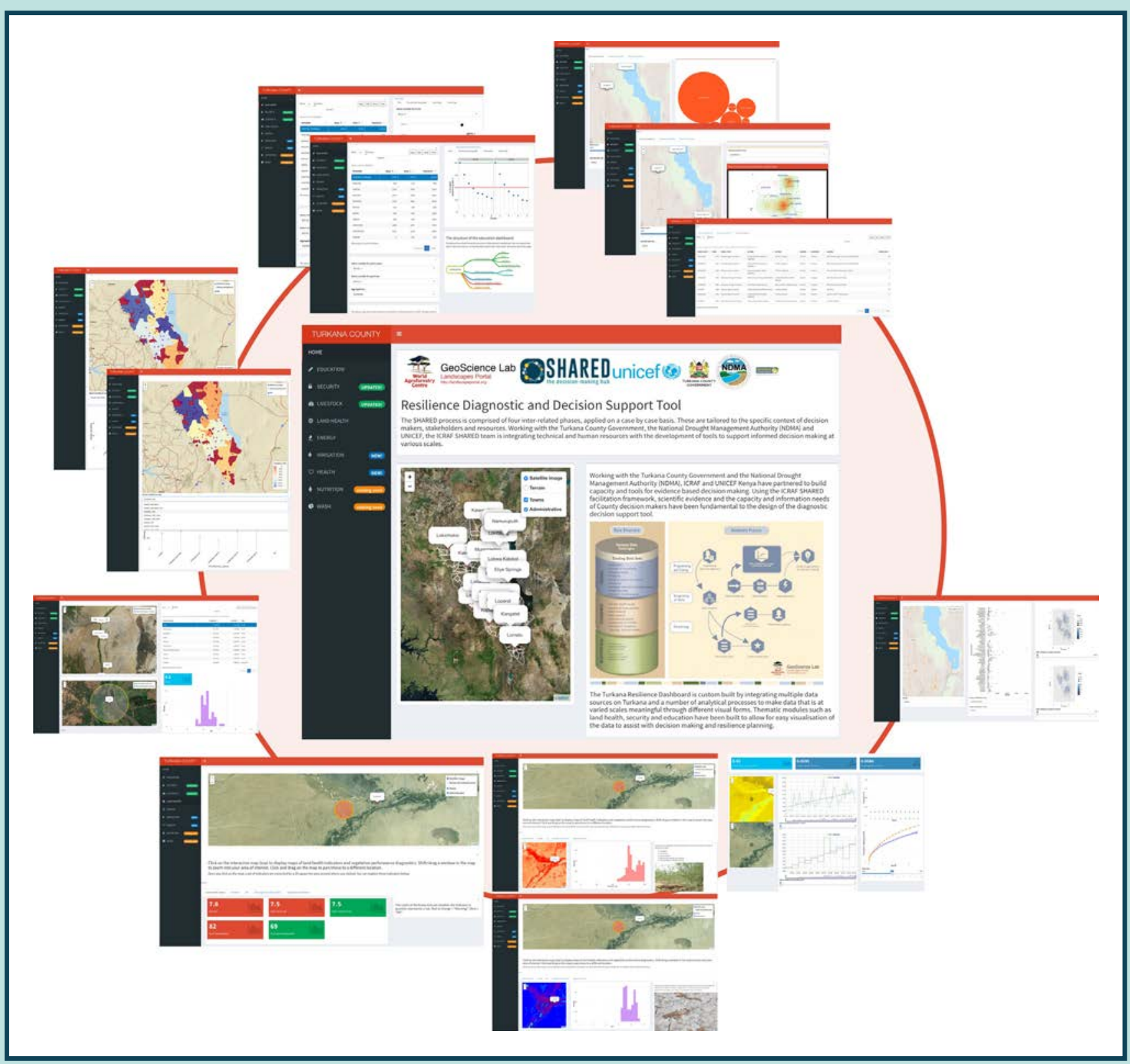




\section{RESILIENCE DIAGNOSTIC AND DECISION SUPPORT TOOL MANUAL}

\section{LANDING PAGE}

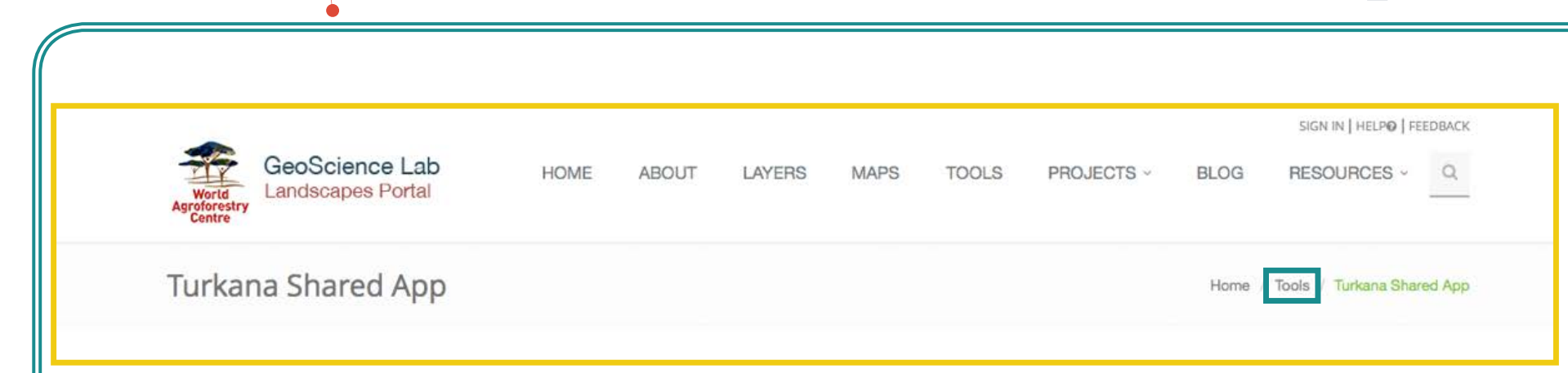

http://landscapeportal.org/turkanaSHARED/

Current Modules for Turkana

County. Select

one by clicking

here.

Click here to hide the menu and modules, and enter a full screen.

Turkana County Map

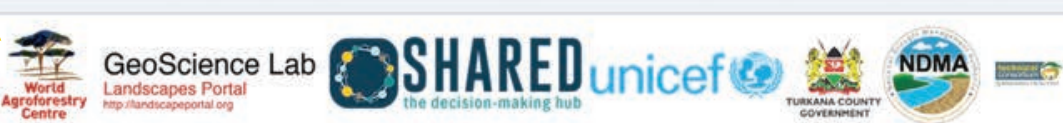

GPDARED

Croario:

Resilience Diagnostic and Decision Support Tool

The SHARED process is comprised of four inter-related phases, applied on a case by case basis. These are tailored to the specific context of decision makers,

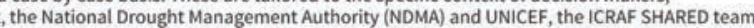
is integrating technical and human resources with the development of tools to support informed decision making at various scales.

$$
\text { . }
$$

(Mем

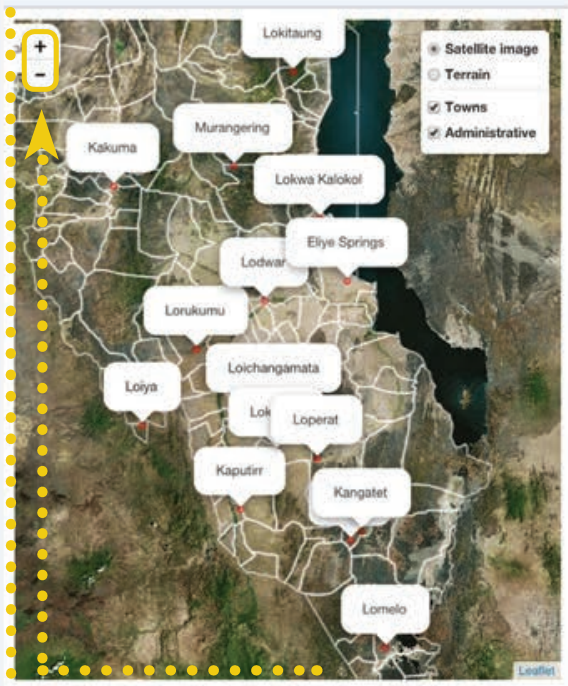

Working with the Turkana County Government and the National Drought Management Authority (NDMA), ICRAF and UNICEF Kenya have partnered to build capacity and tools for evidence based decision making. Using the ICRAF SHARED facilitation framework, scientific fundamental to the design of the diagnostic decision support tool.
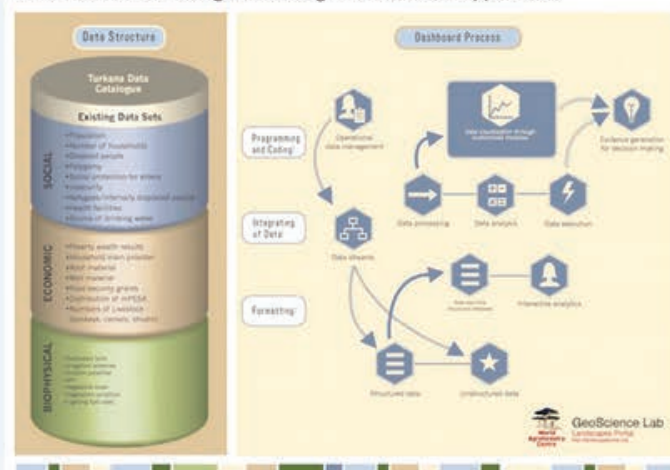

The Turkana Resilience Dashboard is custom built by integrating multiple data sources on Turkana and a number of analytical processes to make data that is at varied scales meaningful through different visual forms. Thematic modules such as land health, security and education resilience planning.
Zoom in (click +) and out (click -) of

+ the map here. Alternatively doubleclick to zoom in, or use your mouse to pan (move) the map. 
WAYS TO VIEW THE MAP
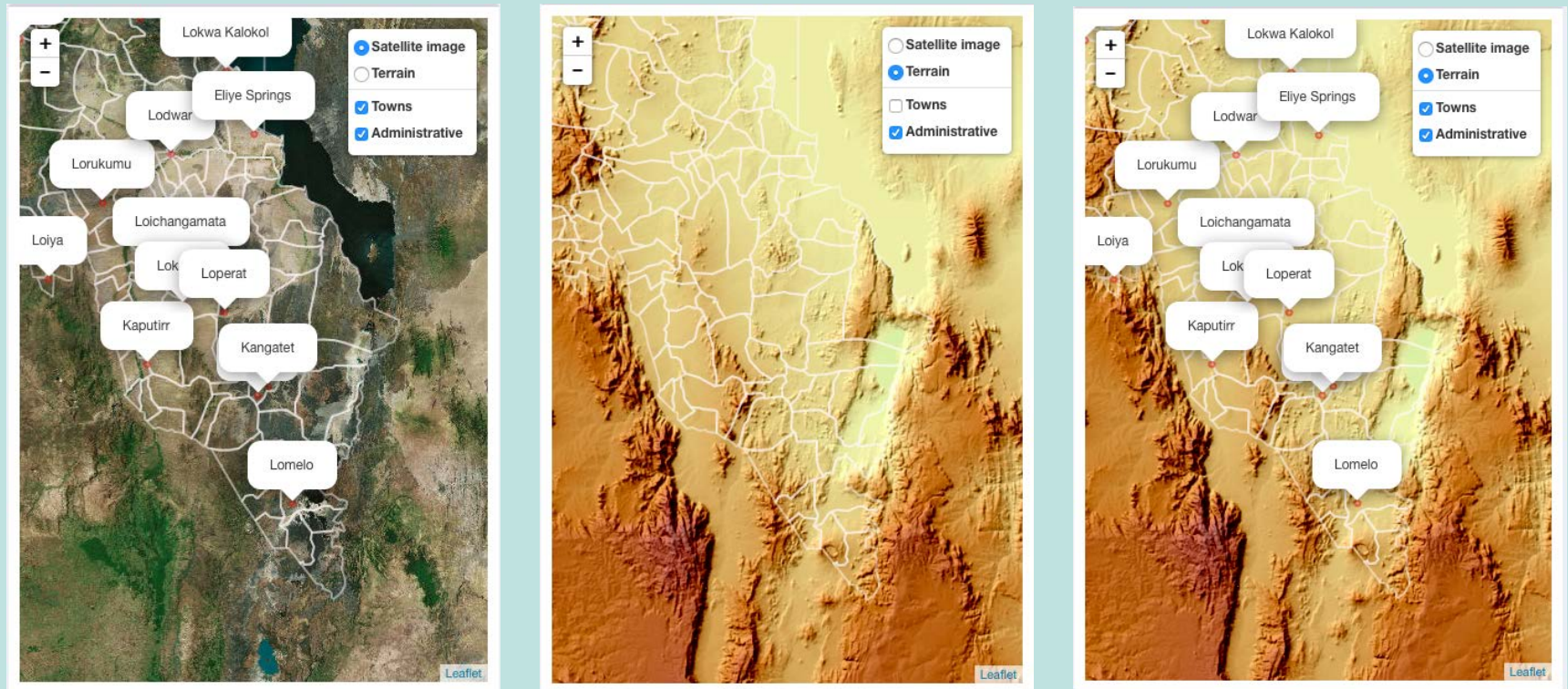

TURKANA RESILIENCE DIAGNOSTIC AND DECISION SUPPORT TOOL

Working with the Turkana County Government and the National Drought Management Authority (NDMA) ICRAF and UNICEF Kenya have partnered to build capacity and tools for evidence based decision-making. Using the ICRAF SHARED facilitation framework, scientific evidence and the capacity and information needs of Turkana County decision makers have been fundamental to the design of the diagnostic decision support tool.
The Turkana Resilience Dashboard is custom built by integrating multiple data sources on Turkana and a number of analytical processes to make data that is at varied scales meaningful through different visual forms. Thematic modules such as land health, security and education have been built to allow for easy visualization of the data to assist with decision making and resilience planning.

The diagnostic dashboard allows for robust management of data for Turkana County with all the data storied in a safe central server. The powerful analytical 'engine' behind the dashboard allows the for the decision maker to select the desired visualizations of the data and carry out various queries and subsequent capacity to download the required information.

Turkana County Government officials were guided through an interactive demonstration session to navigate through each of the modules of the tool. A team of GIS experts and lead by the ICRAF GeoScience Head Dr Tor Vagen who has developed the dashboard facilitated this demonstration session. The demonstration workshop allowed for detailed interrogation and trialing of the dashboard amongst all the workshop participants. 


\section{DATA MANAGEMENT FOR TURKANA COUNTY}

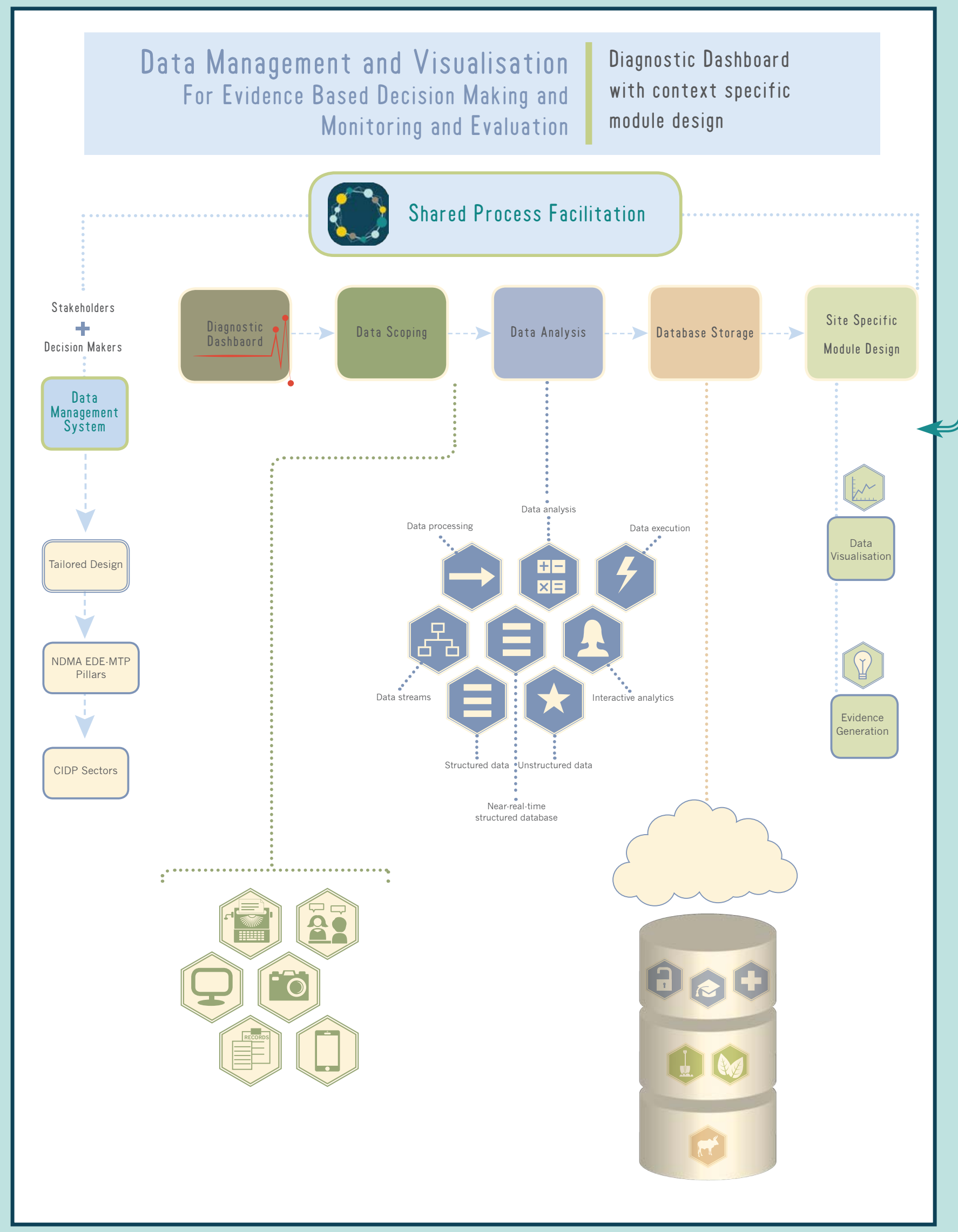




\section{ASSEMBLING DATA SETS \& MODULES}
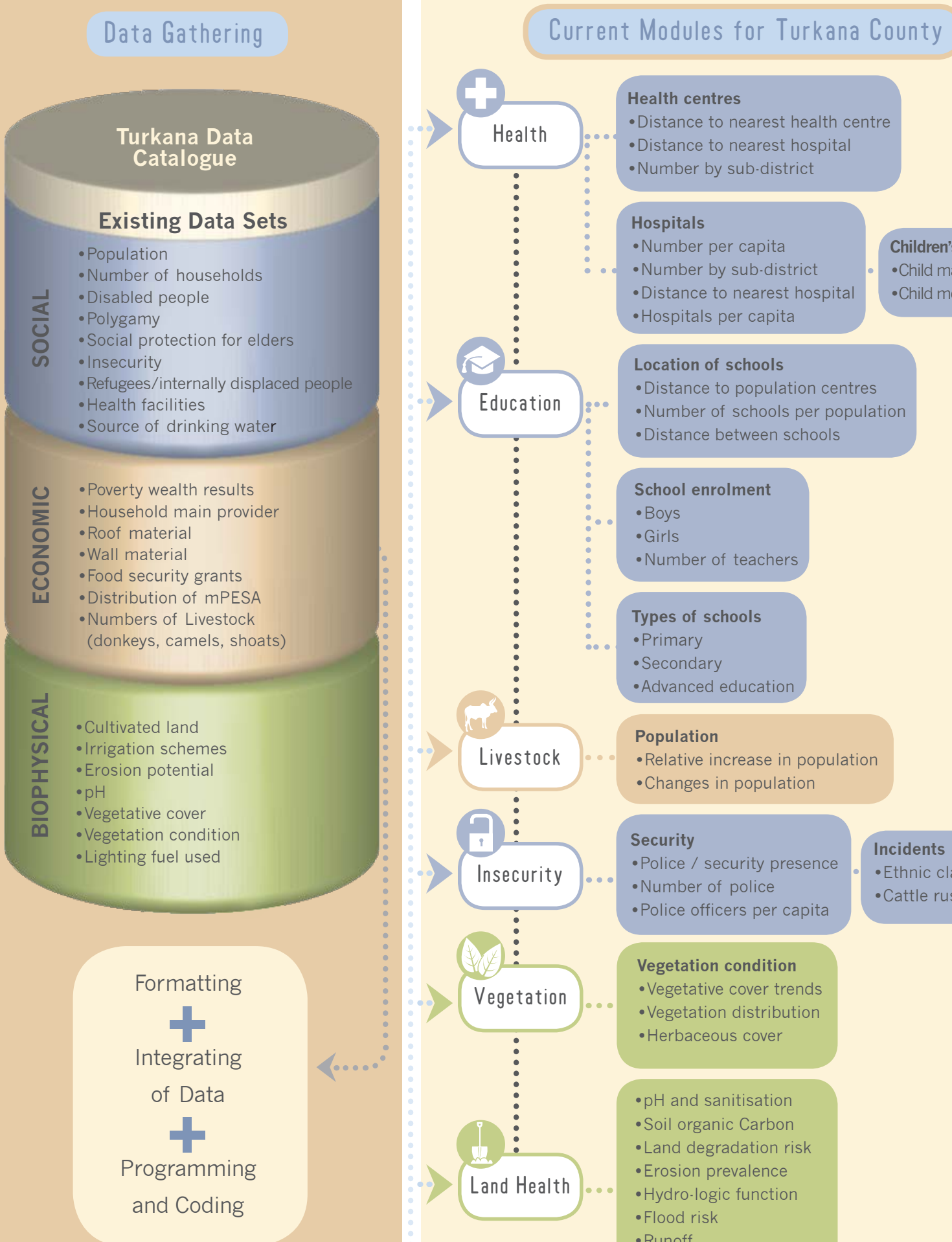

Children's health

Child malnutrition

- Child mortality

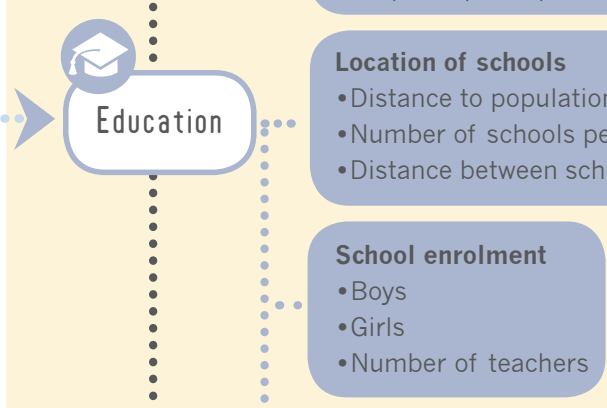

Types of schools

- Primary

- Secondary

- Advanced education

\section{Population}

- Relative increase in population

- Changes in population

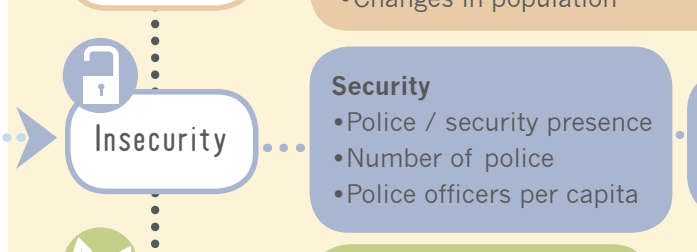

Incidents

- Ethnic clashes

- Cattle rustling

Vegetation condition

- Vegetative cover trends

- Vegetation distribution

- Herbaceous cover

pH and sanitisation

- Soil organic Carbon

- Land degradation risk

- Erosion prevalence

-Hydro-logic function

- Flood risk

- Runoff

- Infiltration capacity

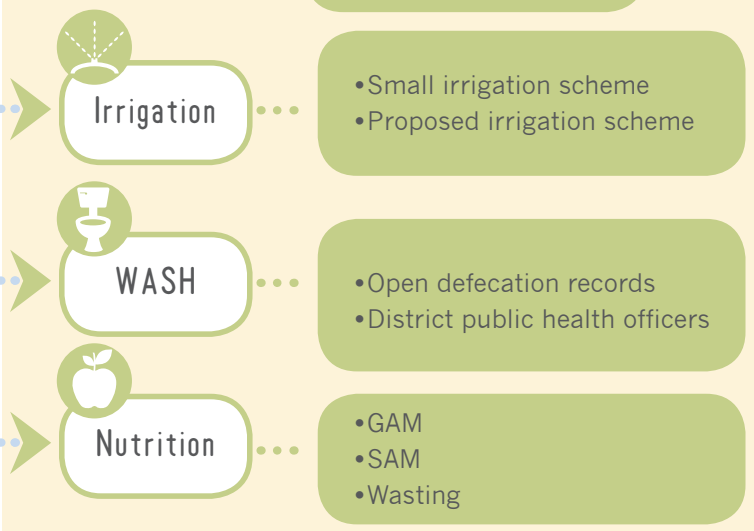




\section{TURKANA COUNTY DATA CATALOGUE}

\begin{tabular}{lll}
\hline TITLE & DESCRIPTION & TYPE \\
EDUCATION & Location of schools in Turkana County - 2007 & Spatial points \\
\hline Location of schools & Enrollment in schools in Turkana County - 2012 & Spatial points \\
\hline Enrollment 2012 & Enrollment in schools in Turkana County - 2014 & Spatial points \\
\hline Enrollment 2014 & $\begin{array}{l}\text { Georeferenced points with security incidents } \\
\text { based mostly on media reports. Source: ACLED }\end{array}$ & Spatial points \\
\hline Turkana insecurity & $\begin{array}{l}\text { Based on HSNP HH surveys - aggregated to } \\
\text { village level } \\
\text { Bumber of shoats per HH }\end{array}$ & $\begin{array}{l}\text { Spatial points / } \\
\text { areas }\end{array}$ \\
\hline village level & $\begin{array}{l}\text { Spatial points / } \\
\text { areas }\end{array}$
\end{tabular}

\section{in. LAND HEALTH}

Soil erosion prevalence

Soil organic carbon (SOC)

Soil $\mathrm{pH}$

Vegetation cover
Soil erosion prevalence for Turkana County at 500m resolution. Source: Vagen, T.-G., World Agroforestry Centre

Soil organic carbon for Turkana County at $500 m$ resolution. Source: Vagen, T.-G., World Agroforestry Centre

Soil pH for Turkana County at 500 m resolution. Source: Vagen, T.-G., World Agroforestry Centre

Vegetation cover maps for Turkana County at $250 \mathrm{~m}$ resolution - taken every 16 days from 2000 to current
Raster image

Raster image

Raster images

Raster images

\section{ENERGY}

Cooking fuel

Lighting fuel

\section{Hydrology / water}

Rivers

Lakes

Water Points

Irrigation Schemes
Cooking energy sources by household, based on Spatial points the HSNP HH survey for Turkana County.

Lighting energy sources by household, based on Spatial points the HSNP HH survey for Turkana County.

Major rivers in Turkana

Spatial lines

Major lakes in Turkana

Spatial polygons

Water points (e.g. wells, small dams and watering holes in Turkana County)

Spatial points

Spatial points

Irrigation schemes (existing and planned) for

Turkana County 


\section{TITLE}

\section{HEALTH}

$\begin{array}{lll}\text { Health centers } & \text { Location of health centers in Turkana County } & \text { Spatial points } \\ \text { HIV prevalence } & \text { HIV data by constituency - children and adults } \\ \text { Treatment facilities for HIV } & \begin{array}{l}\text { Treatment facilities for HIV patient by } \\ \text { constituency in Turkana County }\end{array}\end{array}$

\section{(1) NUTRITION}

$\begin{array}{lll}\text { Wasting } & \text { Wasting data by constituency in Turkana County. Table } \\ & \text { Source: UNICEF } & \\ \text { Stunting } & \text { Stunting data by constituency in Turkana } & \text { Table } \\ & \text { County. Source: UNICEF } & \end{array}$

\section{WASH}

WASH indicators

WASH indicators by constituency in Turkana

Table

County. Source: UNICEF

\section{SOCIO-ECONOMIC}

\begin{tabular}{|c|c|c|}
\hline Poverty / wealth status & $\begin{array}{l}\text { Poverty / wealth status by household, based on } \\
\text { the HSNP HH survey for Turkana County }\end{array}$ & Spatial points \\
\hline Roofing material & $\begin{array}{l}\text { Roofing material by household, based on the } \\
\text { HSNP HH survey for Turkana County }\end{array}$ & Spatial points \\
\hline Wall material & $\begin{array}{l}\text { Wall material by household, based on the HSNP } \\
\text { HH survey for Turkana County }\end{array}$ & Spatial points \\
\hline Social protection & Social protection for older people & Spatial polygons \\
\hline Refugees and IDPS & $\begin{array}{l}\text { Location of refugee camps and IDPs, and their } \\
\text { population }\end{array}$ & Spatial points \\
\hline Tourist attractions & Tourist attraction areas in Turkana & Spatial points \\
\hline 1999 population & population in 1999 & Spatial polygons \\
\hline
\end{tabular}

\section{ADDITIONAL (BACKGROUND DATA USED AS SUPPORTING INFORMATION IN THE ABOVE):}

\begin{tabular}{|c|c|c|}
\hline \multicolumn{3}{|l|}{$\begin{array}{l}\text { Communications and } \\
\text { economy }\end{array}$} \\
\hline MPESA locations & $\begin{array}{l}\text { Distribution and location of MPESA points in } \\
\text { Turkana }\end{array}$ & Spatial points \\
\hline 1999 poverty data & Poverty data in 1999 & polygon \\
\hline Administrative boundaries & $\begin{array}{l}\text { Administrative boundaries for } 1989 \text { / } 1999 \text { / } \\
2009\end{array}$ & Spatial polygons \\
\hline Population census data & Population censuses 1989 / 1999 / 2009 & $\begin{array}{l}\text { Spatial points and } \\
\text { polygons }\end{array}$ \\
\hline Infrastructure & Roads and other general infrastructure & Spatial lines \\
\hline
\end{tabular}




\section{EDUCATION MODULE}

\section{EDUCATION DASHBOARD}

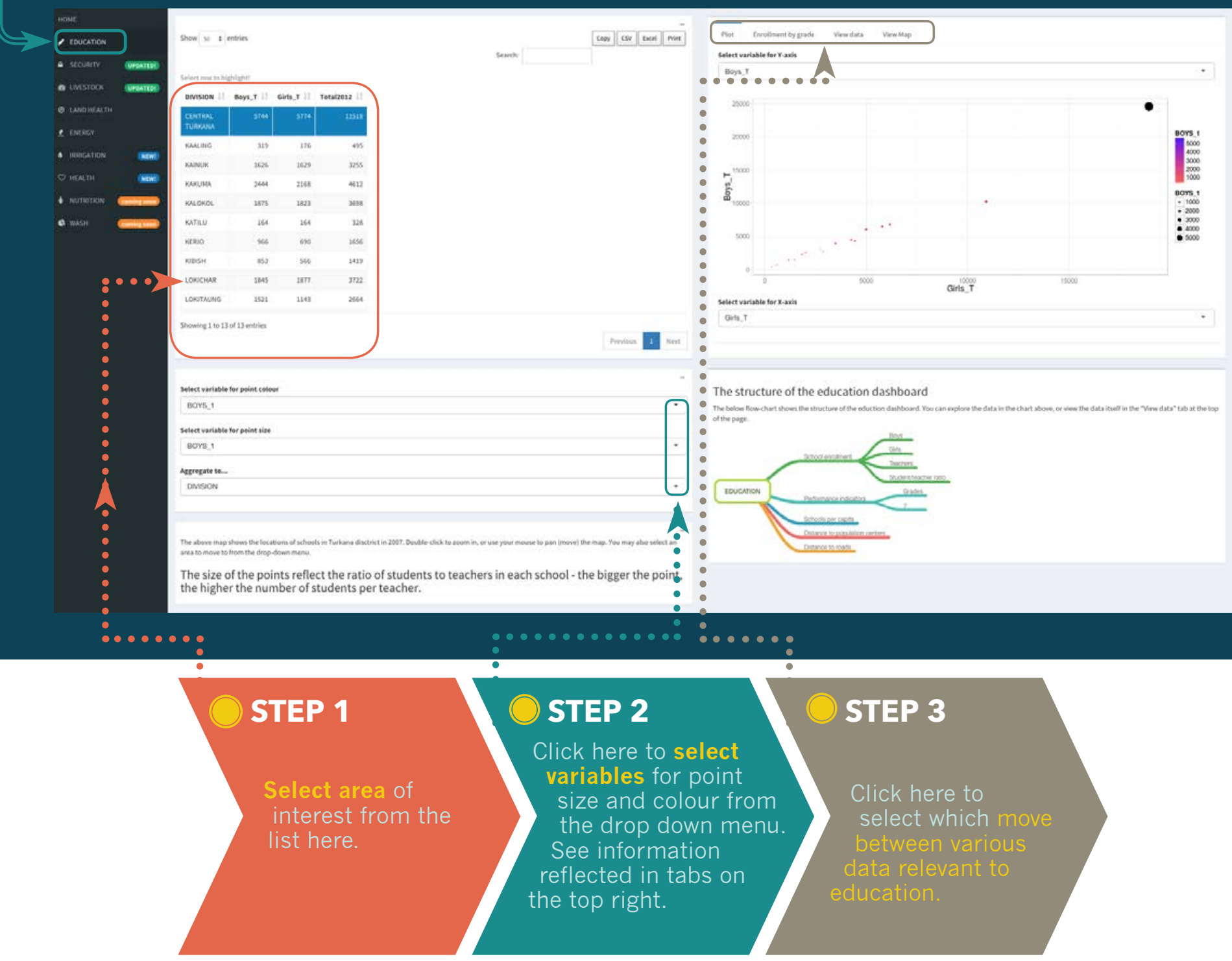

\begin{tabular}{|l|l|l|l|l}
\hline Show $50 \quad$ entries & \\
Select row to highlight! \\
DIVISION 19 Boys_T
\end{tabular}




\begin{tabular}{|l|}
\hline Select variable for point colour \\
\hline GIRLS_3 \\
\hline BOYS_1 \\
BOY__2 \\
BOYS_3 \\
BOYS_4 \\
BOYS_5 \\
BOYS_6 \\
BOYS_7 \\
Dove。 \\
\hline
\end{tabular}

Variable for point colour: Boys Grade 1 8 / Girls Grade 1 - 8 / Boys Total / Girls Total / Total.

\begin{tabular}{|l|}
\hline Select variable for point size \\
\hline BOYS_1 \\
\hline BOYS_5 \\
BOYS_6 \\
BOYS_7 \\
BOYS_8 \\
GIRLS_1 \\
GIRLS_2 \\
GIRLS_3 \\
\hline
\end{tabular}

Variable for point size: Boys Grade 1 - 8 / Girls Grade 1 - 8 / Boys Total / Girls Total / Total.

\begin{tabular}{|l|}
\hline Aggregate to... \\
\hline SCNAME \\
\hline DIVISION \\
ZONE \\
SCNAME \\
\hline
\end{tabular}

Variable for Aggregate to: Division / Zone/ SCName.

\section{ENROLLMENT BY GRADE IN TURKANA COUNTY}

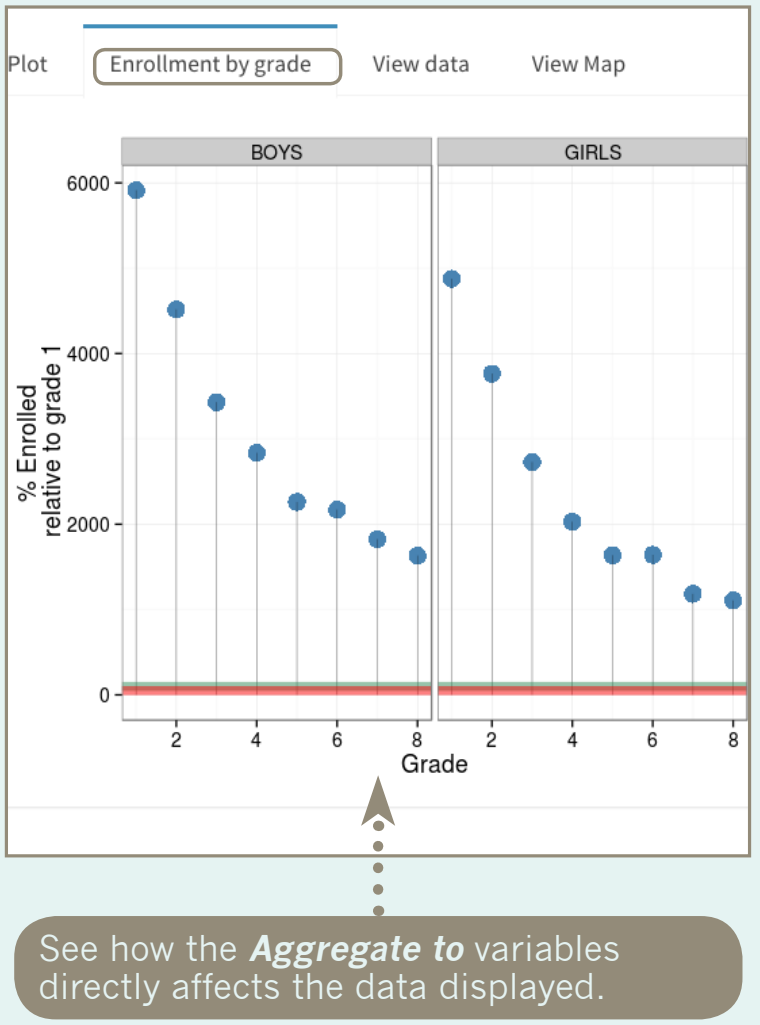

See how the $\mathbf{X}$-axis, $\mathbf{Y}$-axis, and

Aggregate to variables directly affects the data displayed.

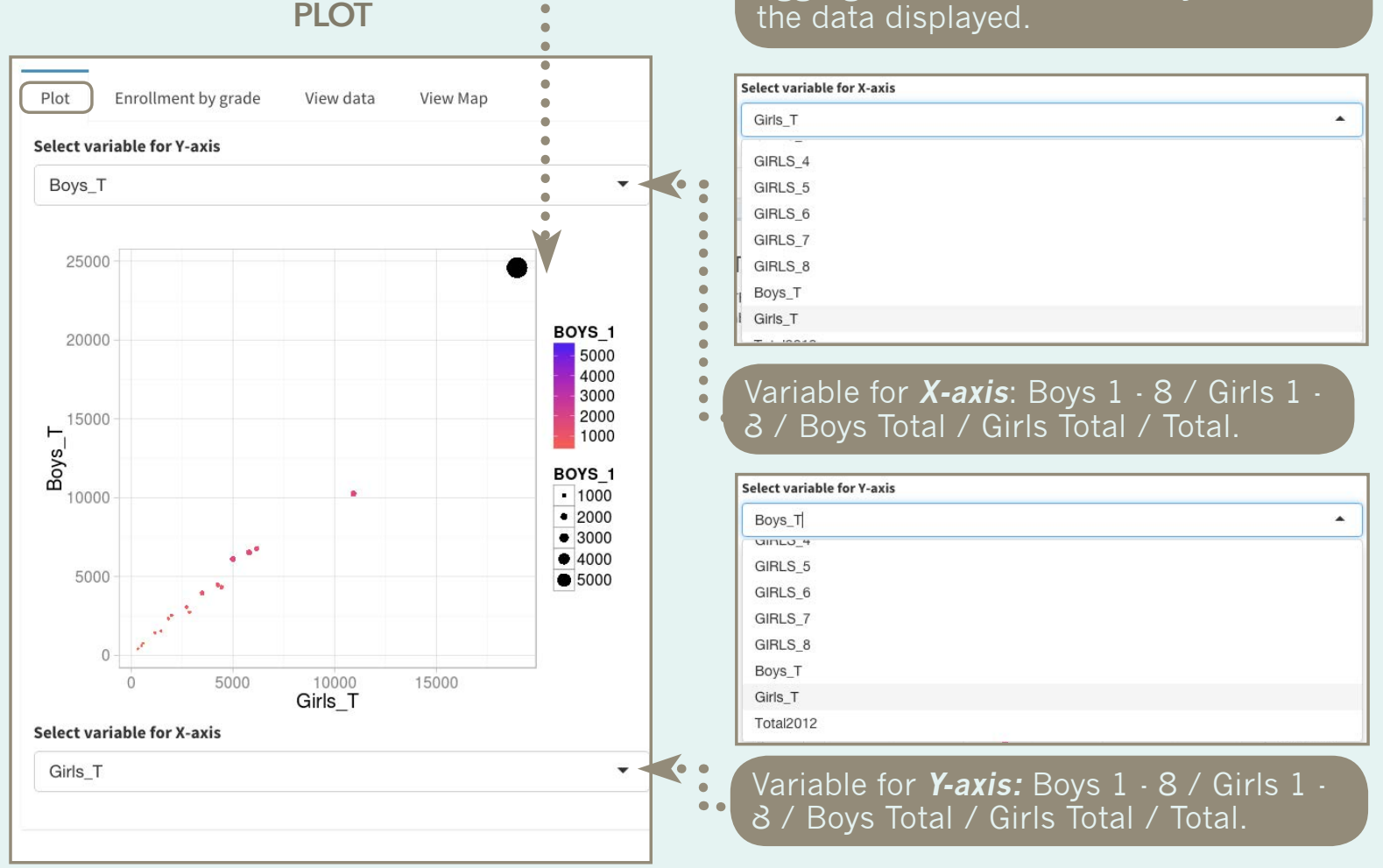




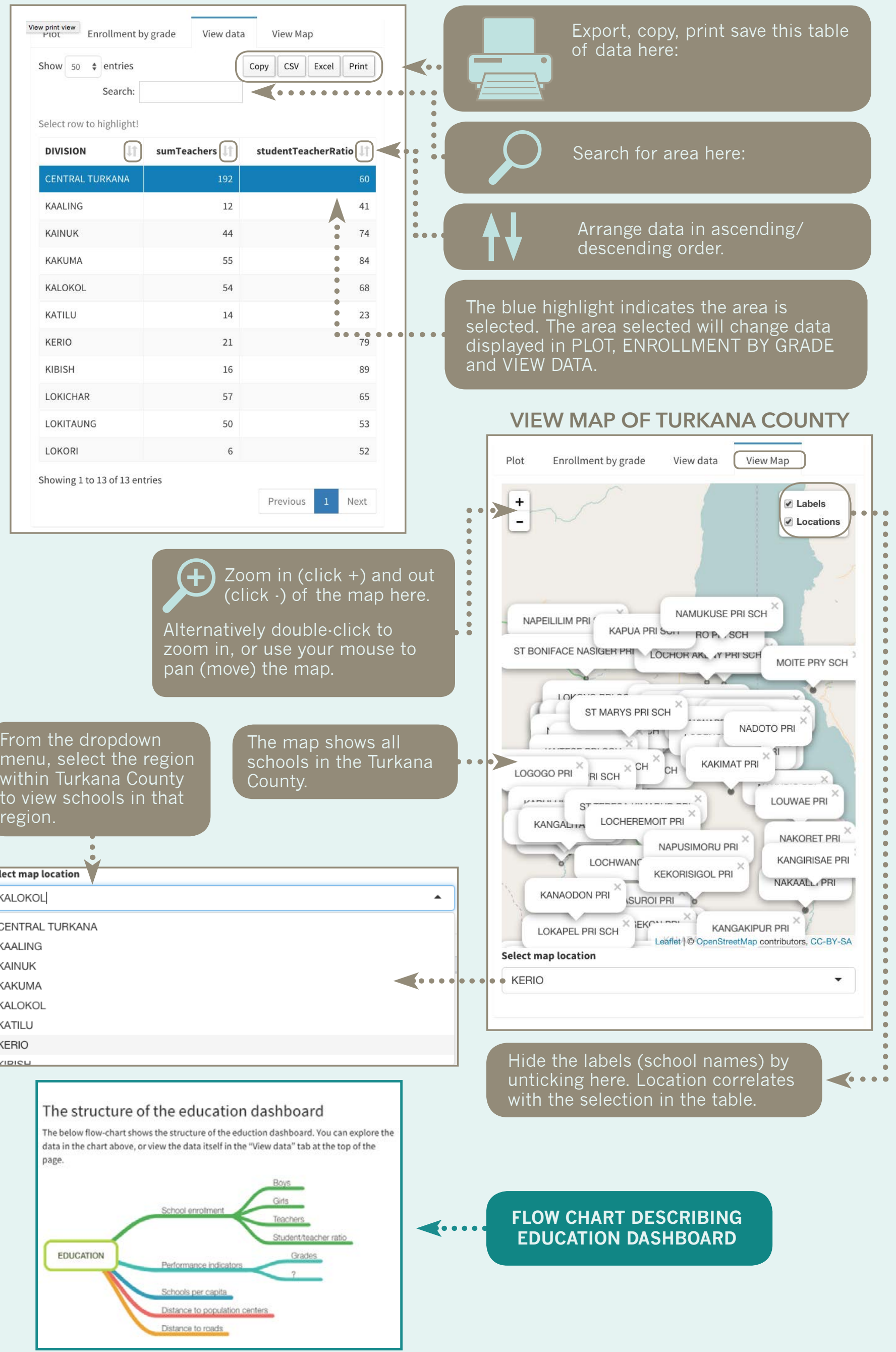



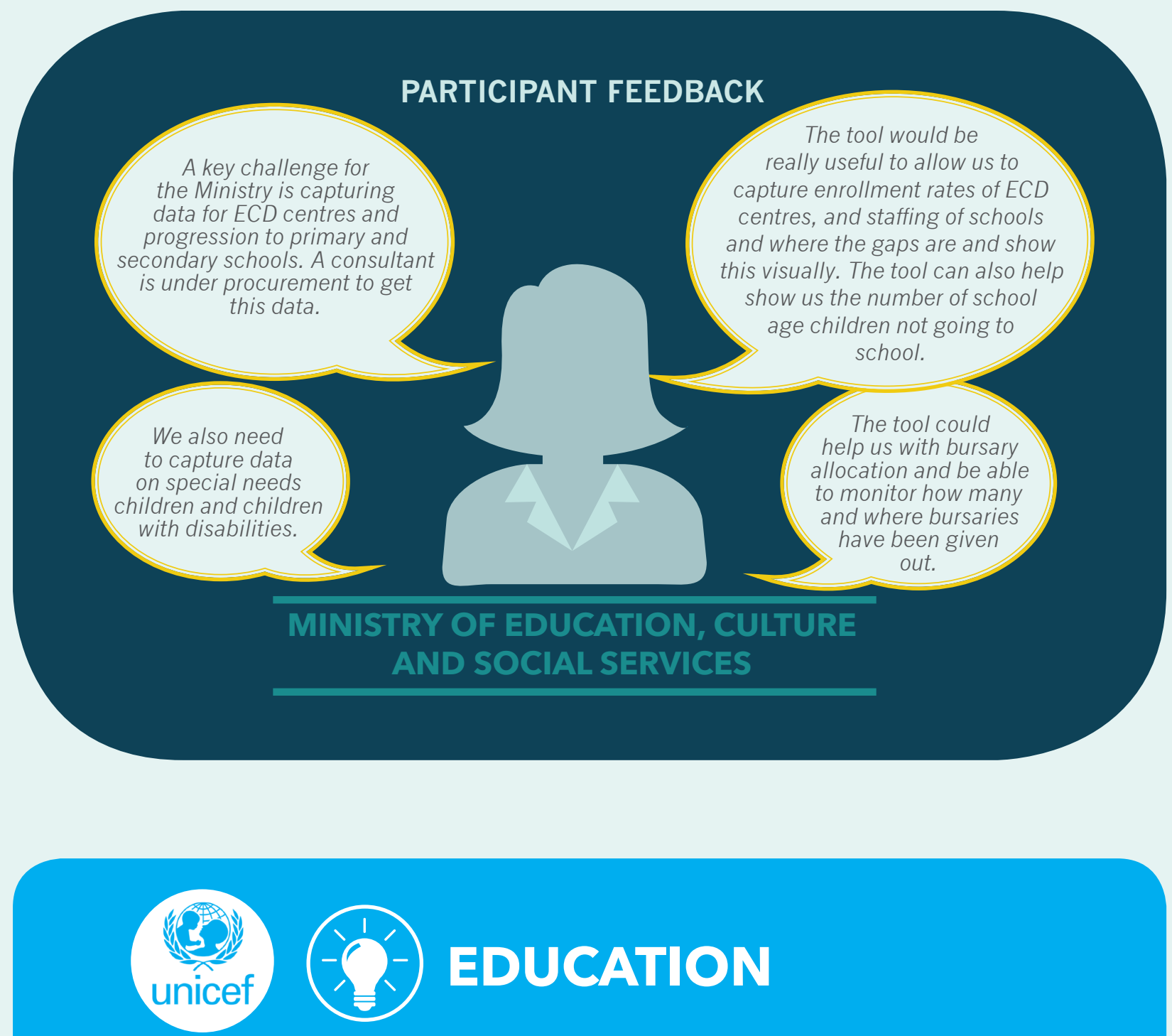

\section{EDUCATION}

Education is a basic human right. Like all human rights, it is universal and inalienable-everyone, regardless of gender, religion, ethnicity or economic status, is entitled to it (http://www. unicef.org/education/index_44870.html) The benefits of education-for national development, individual prosperity, health and social stability-are well known, but for these benefits to accrue children in school have to be learning. Despite commitments and progress in improving access to education at the global level, including Millennium Development Goal (MDG) 2 on universal primary education and the Education for All (EFA) Goals, levels of learning are still too low (LMTF, 2014). In Kenya, nationally there has been an overall increase in the number of children and youth accessing education - as per EMIS 2014 the Net Enrolment Rate (NER) has increased from $80.3 \%$ in 2003 , to $85.2 \%$ NER in 2014. However regional disparities remain, especially in the Arid and SemiArid areas (ASALs) and in refugee camps. Children and adolescents from these areas have the lowest enrolment numbers, particularly for girls, high dropout rates and poor infrastructural development, high pupil teacher ratio, high pupil textbook ratio. Children, adolescents and youth are leaving school without the minimum competencies and the necessary skills and knowledge. In Turkana, the NER stands at 59\% with 119,494 (57\% girls) school-aged children out of school. These statistics do not take into account disparities between urban and rural areas. 


\section{SECURITY MODULE}

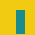

\section{SECURITY DASHBOARD}

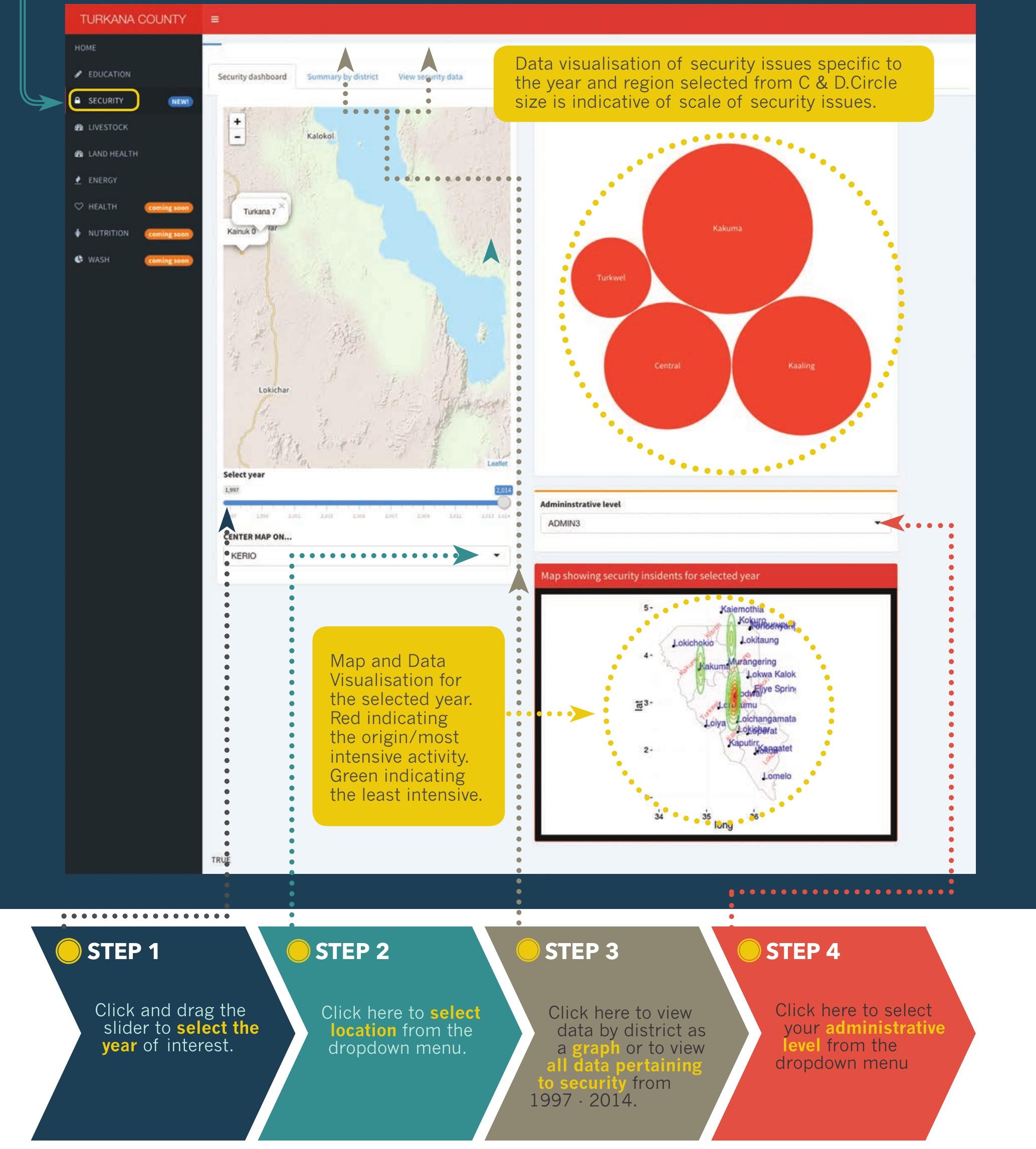




\begin{tabular}{|c|c|}
\hline \multicolumn{2}{|l|}{ CENTER MAP ON... } \\
\hline KERIO| & - \\
\hline KIBISH & \\
\hline LOKICHAR & \\
\hline LOKICHOGGIO & \\
\hline LOKITAUNG & \\
\hline LOKORI & \\
\hline LOMELO & \\
\hline OROPOI & \\
\hline
\end{tabular}

Variable for area where you would like the map to center on

Refine data by entering

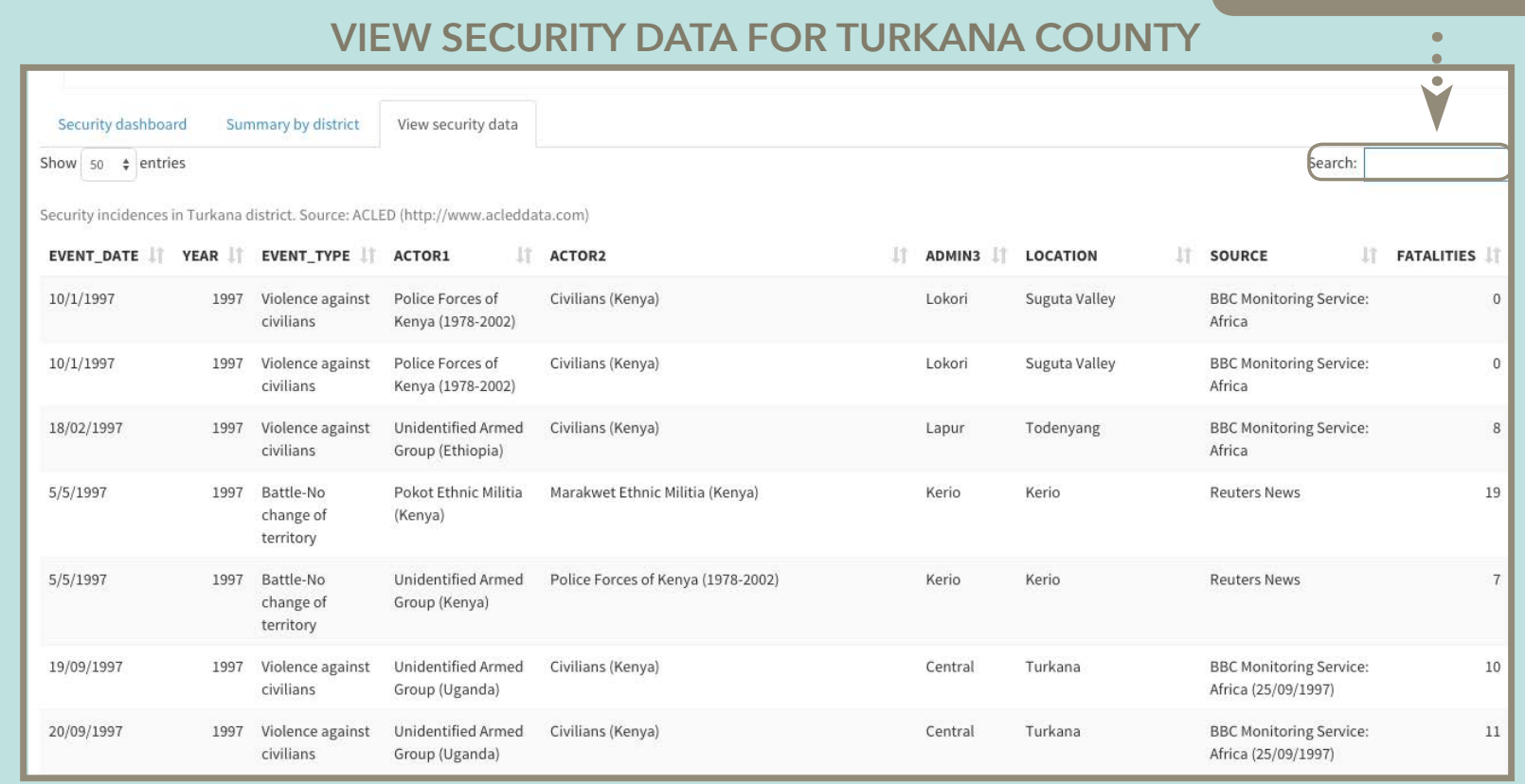

SUMMARY BY TURKANA COUNTY DISTRICT (ALL DATA)

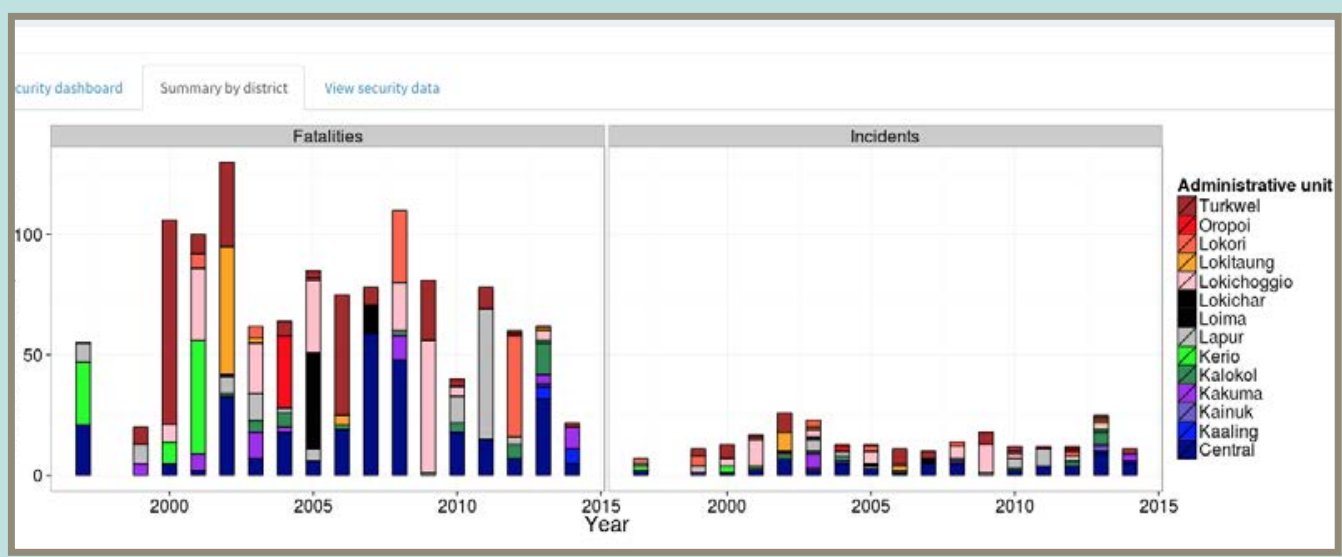
key words in here 


\section{LIVESTOCK MODULE 4}

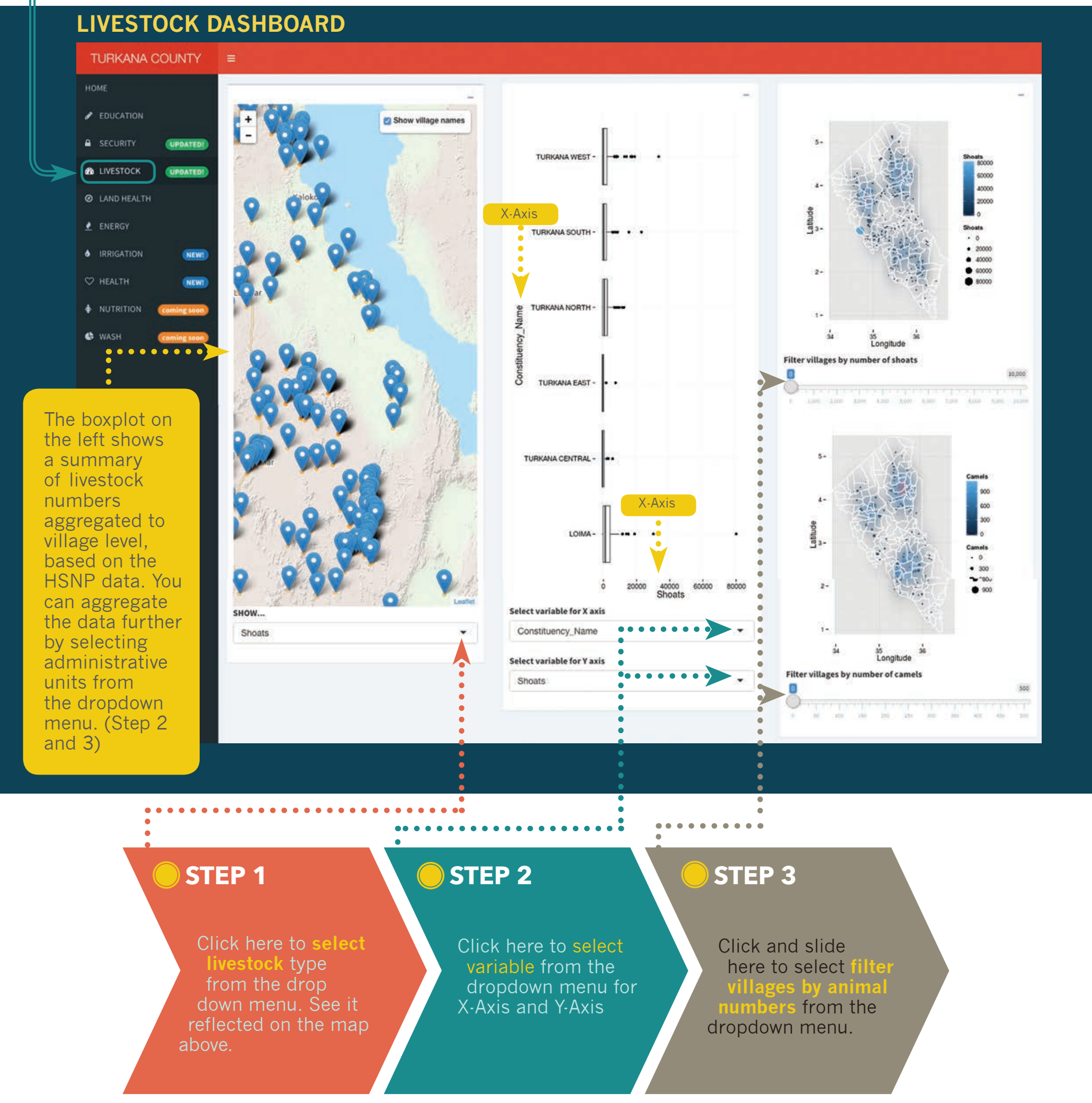




\begin{tabular}{|l|}
\hline SHOW... \\
\hline Camels \\
Shoats \\
Camels
\end{tabular}

Variable for Map: Shoats / Camels.

\begin{tabular}{l} 
Select variable for $\mathbf{X}$ axis \\
Constituency_Name \\
\hline Constituency_Name \\
Division_Name \\
Location_Name
\end{tabular}

Variable for X-Axis: Constituency Name / Division Name / Location Name.

\begin{tabular}{l} 
Select variable for $\mathrm{Y}$ axis \\
Shoats \\
\hline Camels \\
Shoats
\end{tabular}

Variable for Y-Axis: Camels / Shoats

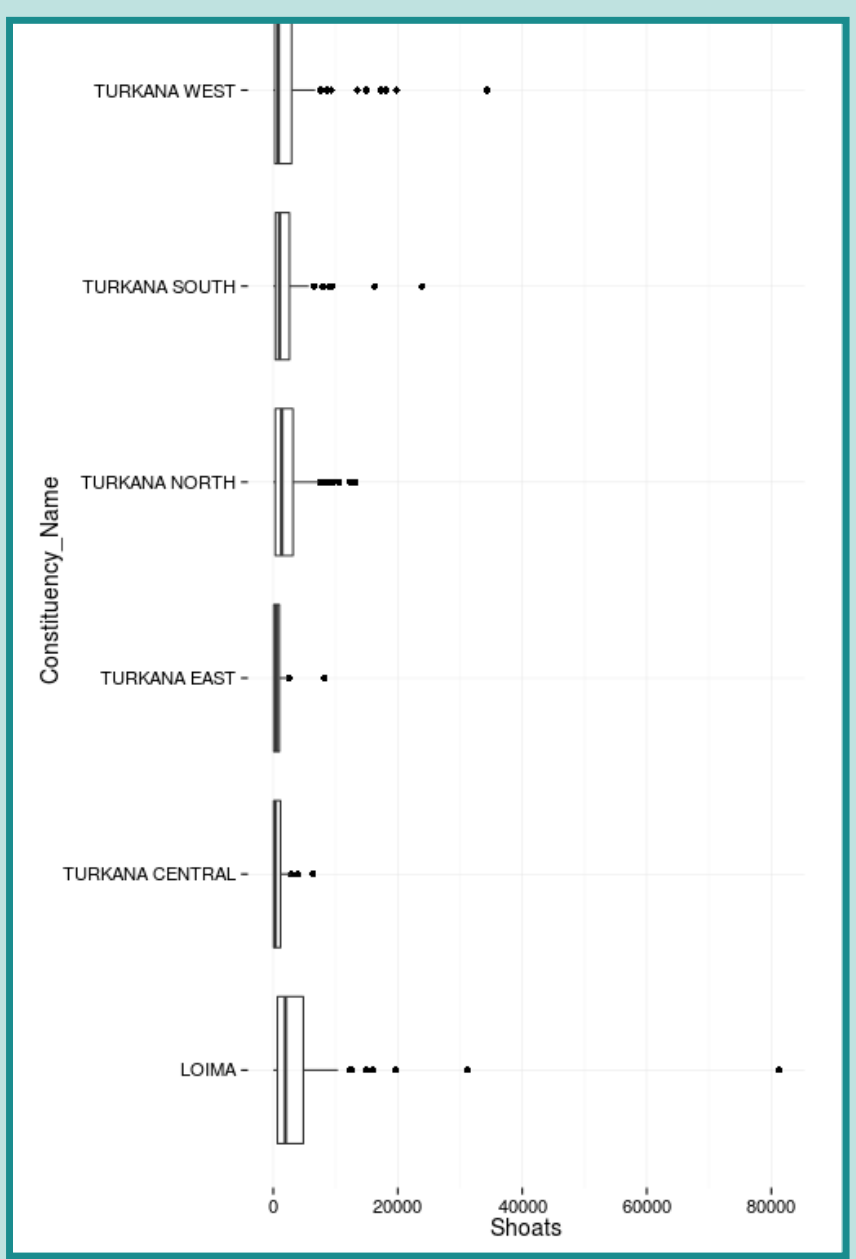

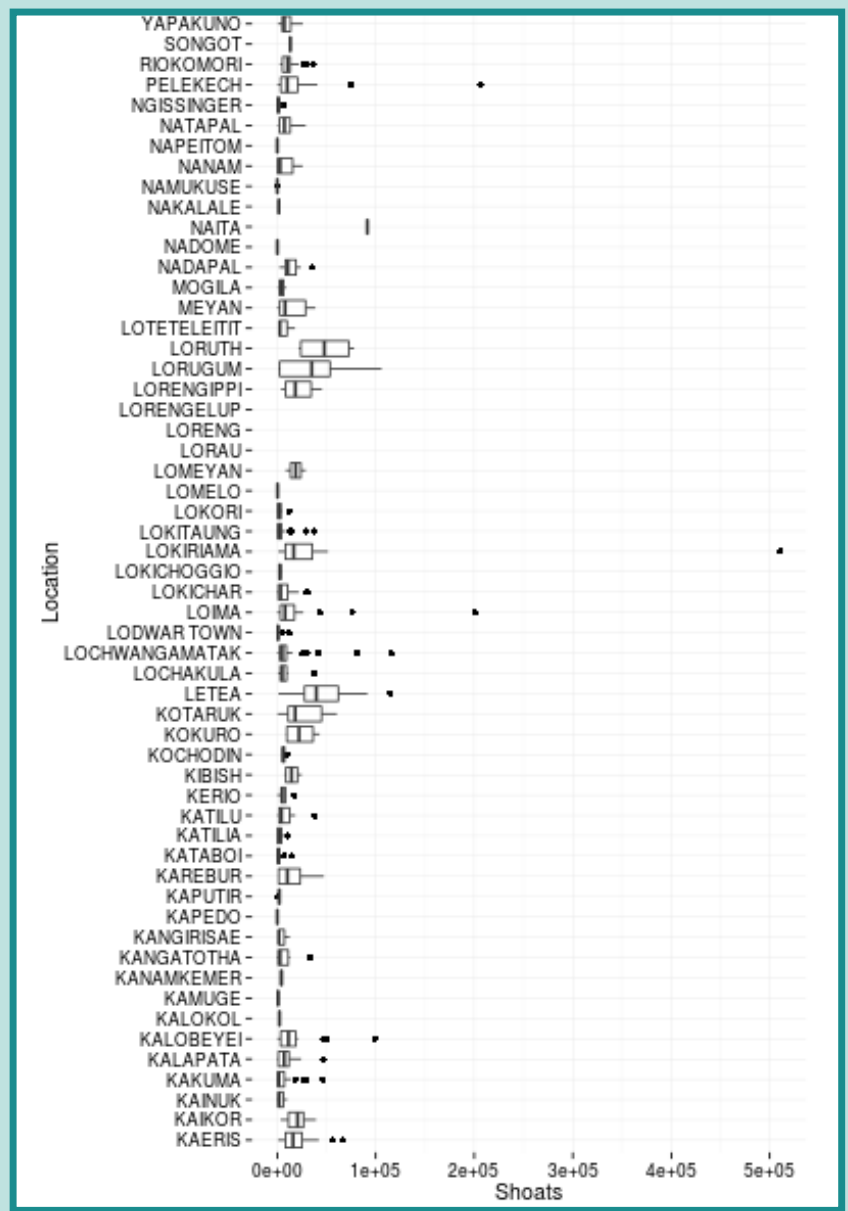

\section{Data Visualisation for Location Name}

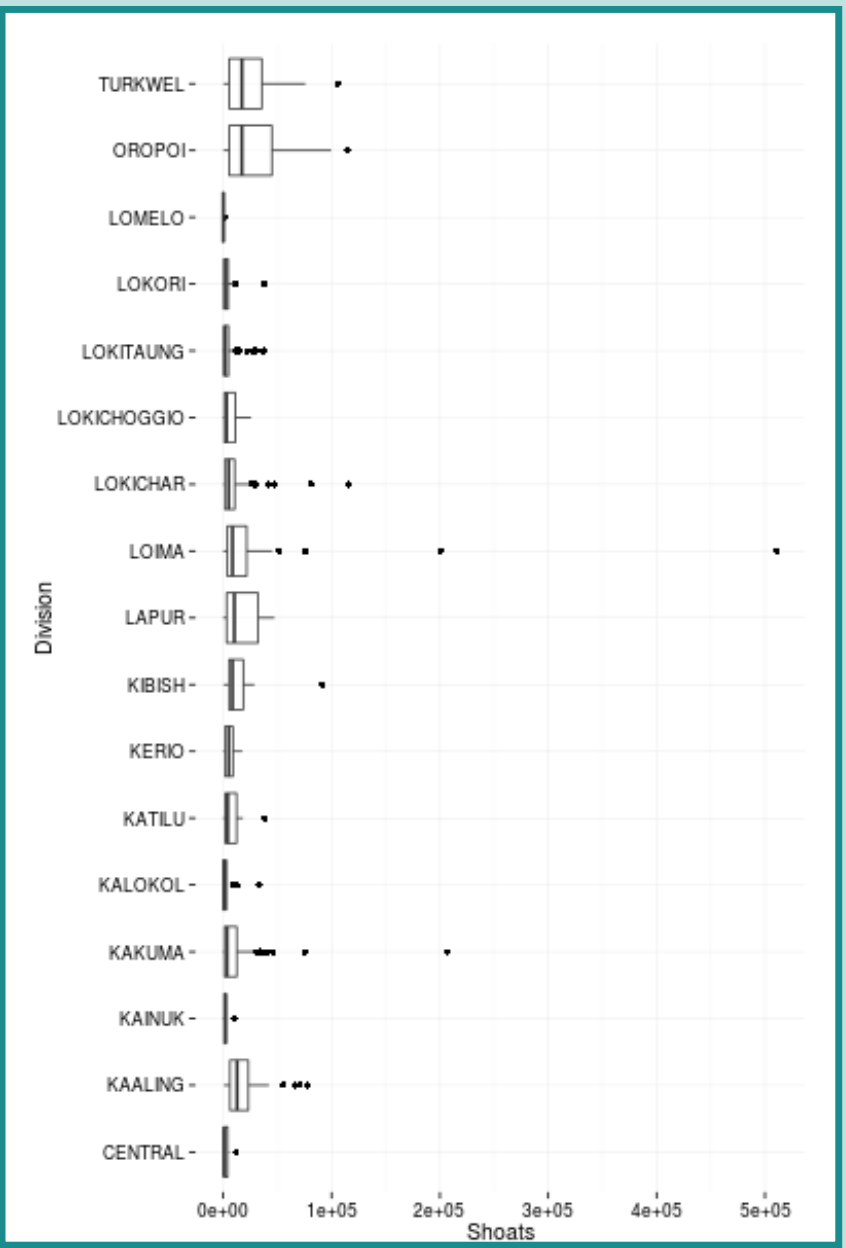

Data Visualisation for Division Name 

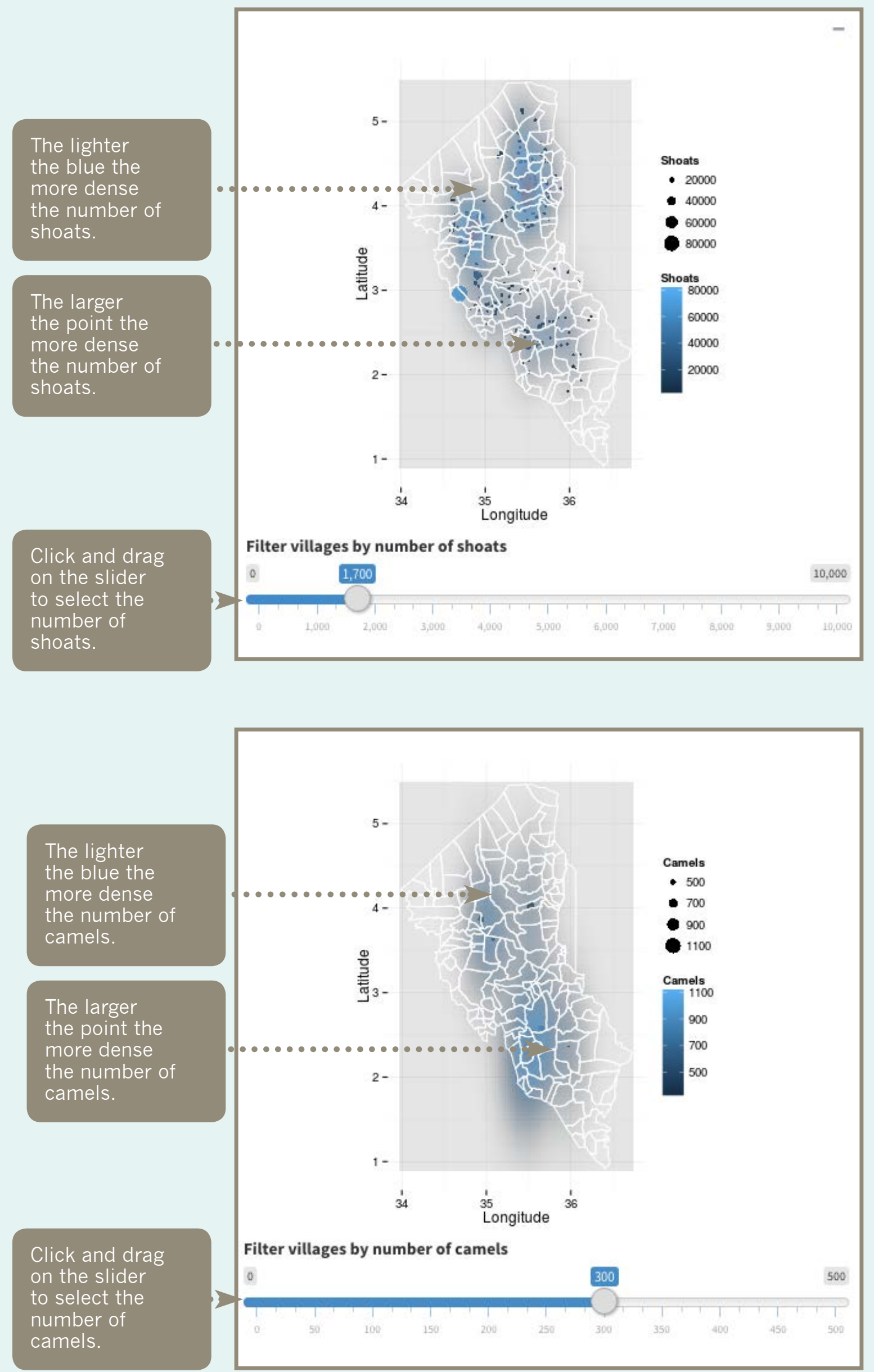

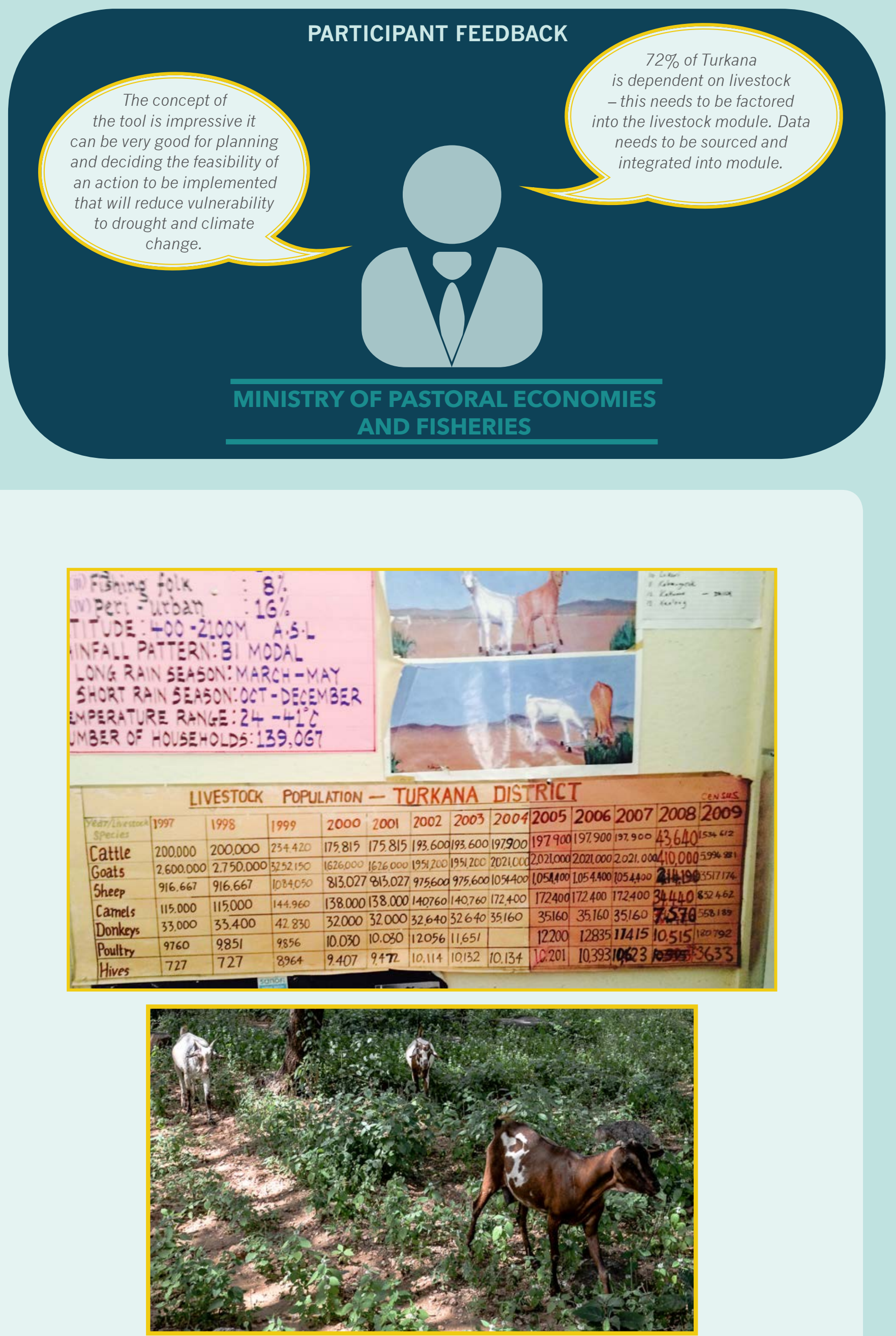


\section{LAND HEALTH MODULE}

\section{LANDHEALTH DASHBOARD}

TURKANA COUNTY $\equiv$

HOME

- education

- SECURITY UPDATEDI

(2) LIVESTOCK UPDATED!

$\geqslant$ LAND HEALTH

$\perp$ ENERGY

- iRRigation NEW

\& HEALTH NU RITION Coming son

Comingsoon

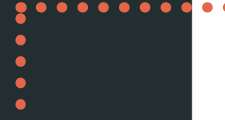

Click on the interactive map (top) to display maps of land health indicators and vegetation performance diagnostics. Shift+drag a window in the map to zoom into your area of interest. Click and drag on the map to pan/move to a different location.

Once you click on the map, a set of indicators are extracted for a 25 square $\mathrm{km}$ area around where you clicked. You can explore these indicators below.
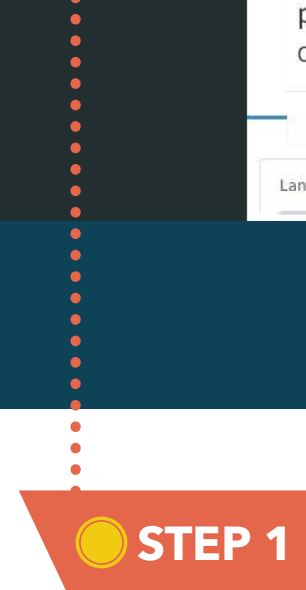

Click on area of interest on the map to get specific information on land health of that location

Land health status Erosion pH Soil organic carbon (SOC) Vegetation condition
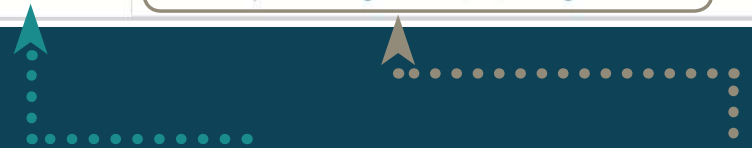

\section{(os}

STEP 2

Once you've selected an area of interest on the map, you can see an overview of indicators specific to the soil in the selected area

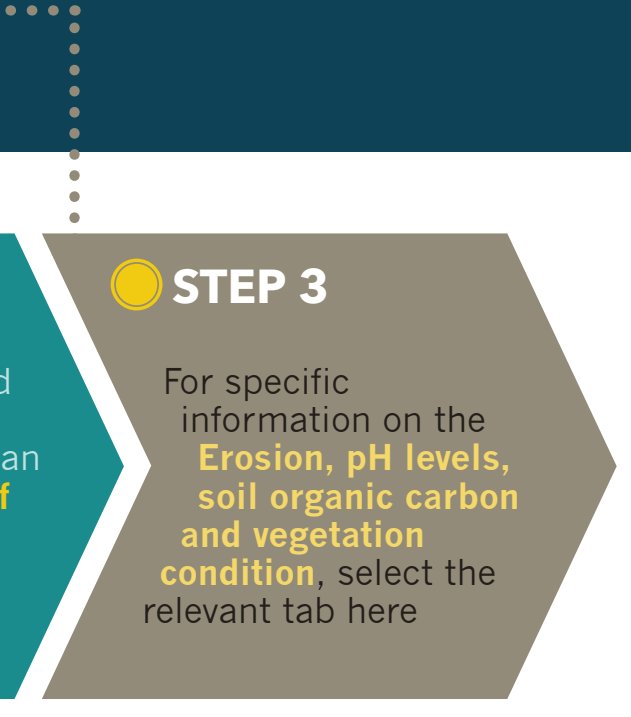

LAND HEALTH STATUS

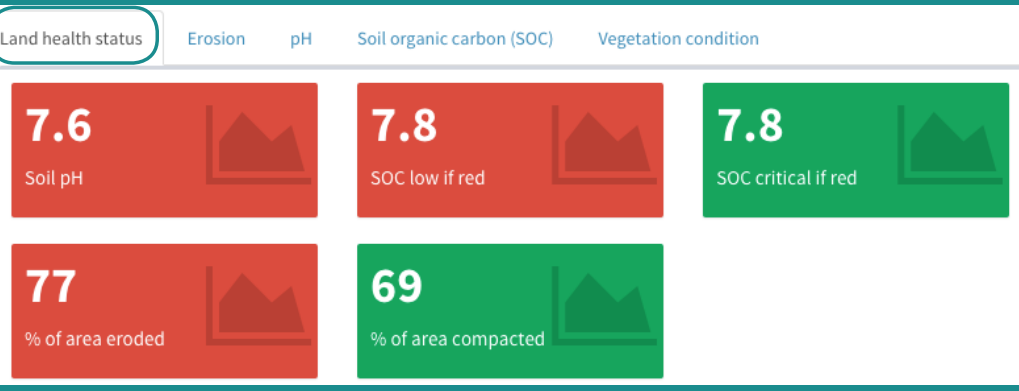

$$
\begin{aligned}
& \text { (1) = WARNING! } \\
& \text { ( }=\text { OK }
\end{aligned}
$$


Soil erosion is an important indicator of land health. It can be the result of a number of processes, including:

- cultivation

- over-grazing

- invasive species

- inherent soil properties (e.g. high pH)

- poor drainage or infiltration capacity

When erosion is severe, it leads to the loss of productive topsoil and also the loss of seed stocks in the soil, especially for grasses. The result is that the grasses do not grow back even when there are good rains.
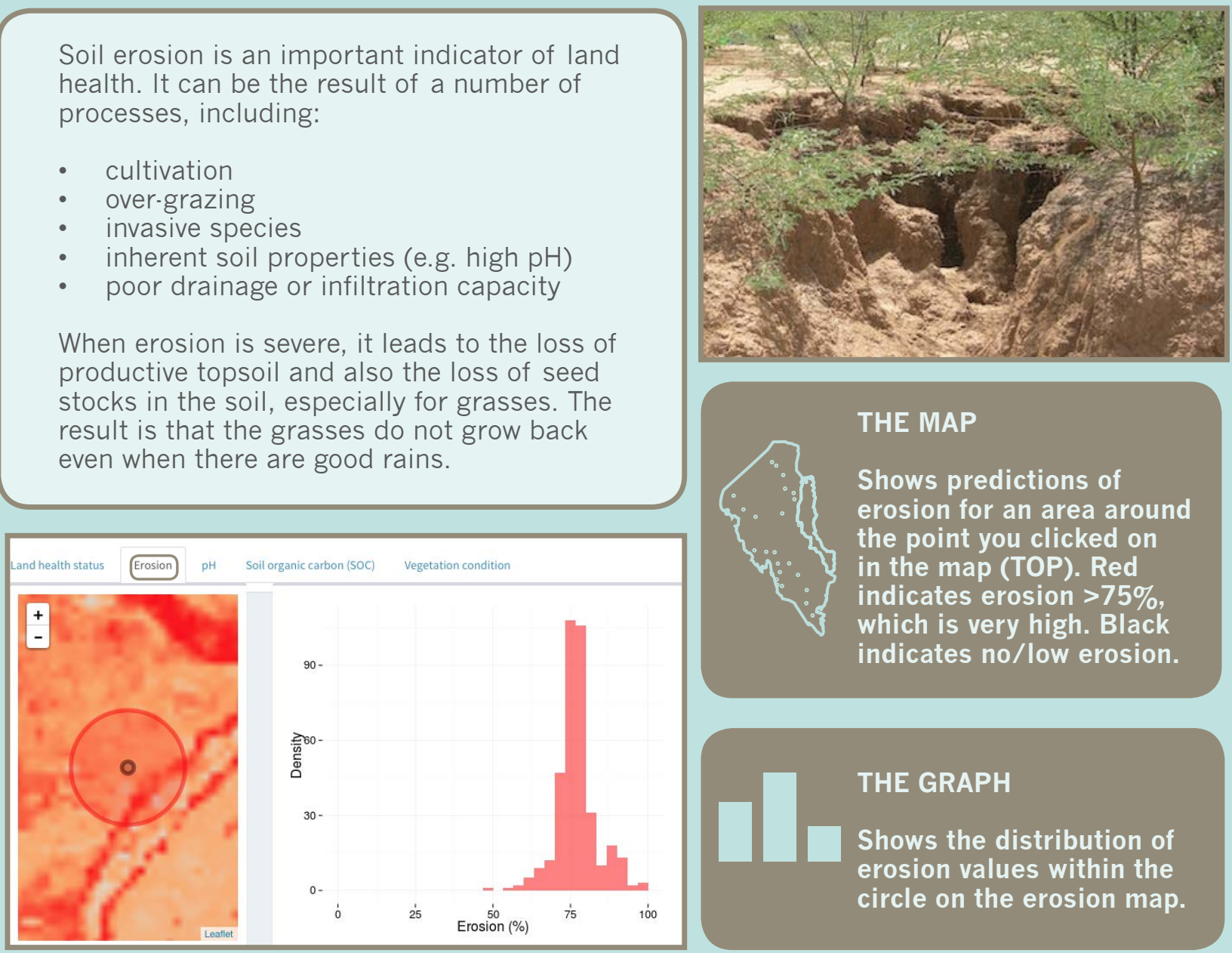

\section{PH - GRAPH AND VISUALISATION OF DATA SPECIFIC TO SELECTED AREA}

Soil $\mathrm{pH}$ is an important indicator of soil health. In the case of Turkana, soils have inherently high $\mathrm{pH}$ values. When $\mathrm{pH}$ values are higher than 7.5 , the soil is generally considered alkaline. At values higher than 8 there is considerable risk of salinisation.

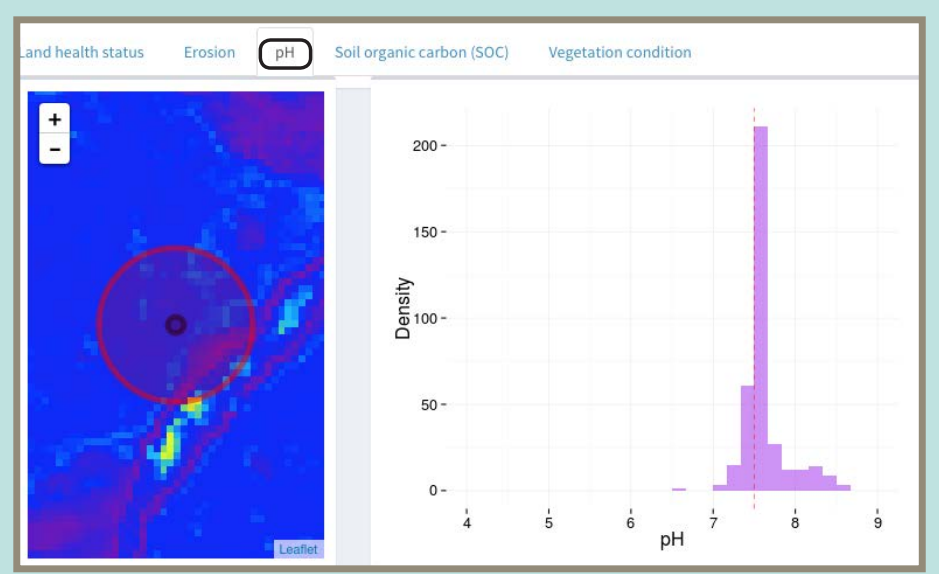

\section{THE MAP}

Shows predictions of $\mathrm{pH}$ for an area around the point you clicked on in the map (TOP). Red indicates low erosion $(<5)$; greenblue between 5 and 7.5 ; purple higher than 7.5 .

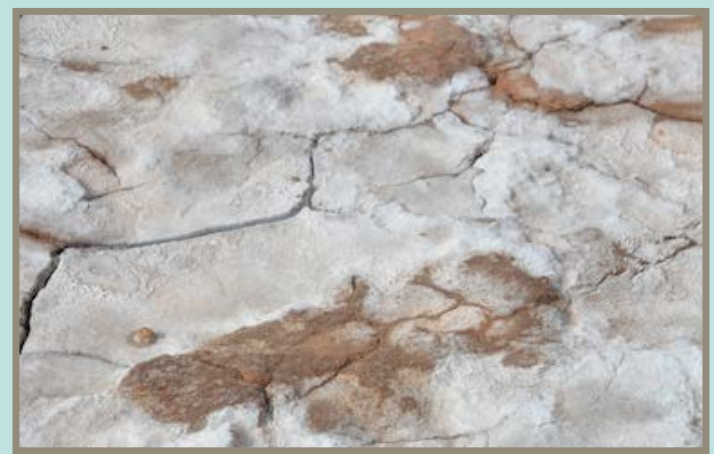



SELECTED AREA

Soil organic carbon (SOC) is an important indicator of soil health, but also regulates a number of other ecosystem functions. These include hydrology (e.g. infiltration capacity). When SOC values are lower than $15 \mathrm{~g} / \mathrm{kg}$, this is generally considered low SOC, however it is when values drop below $5 \mathrm{~g} / \mathrm{kg}$ that we have critically low SOC in the soil.
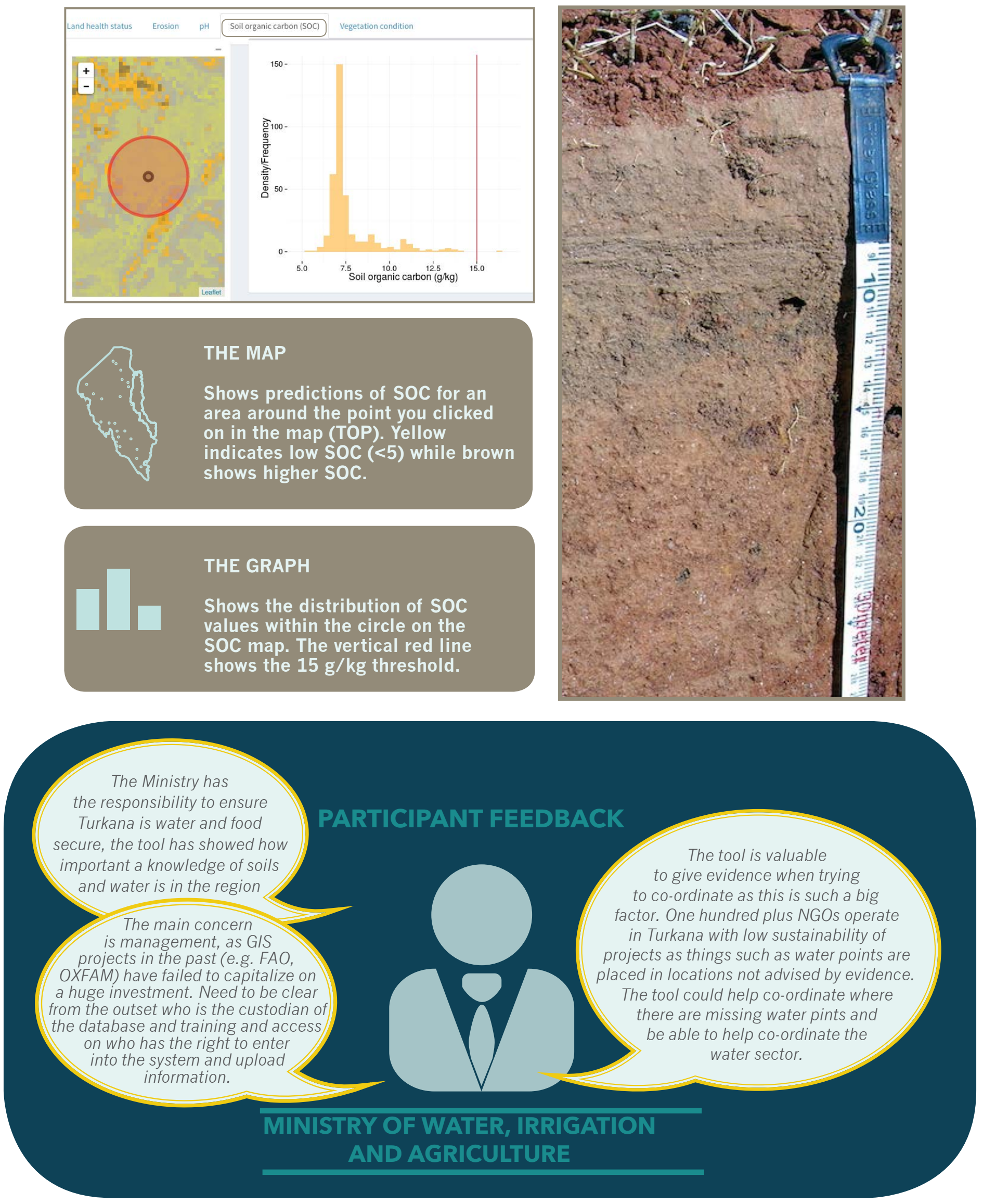


\section{VEGETATION CONDITION - GRAPH AND VISUALISATION OF DATA SPECIFIC TO SELECTED AREA}

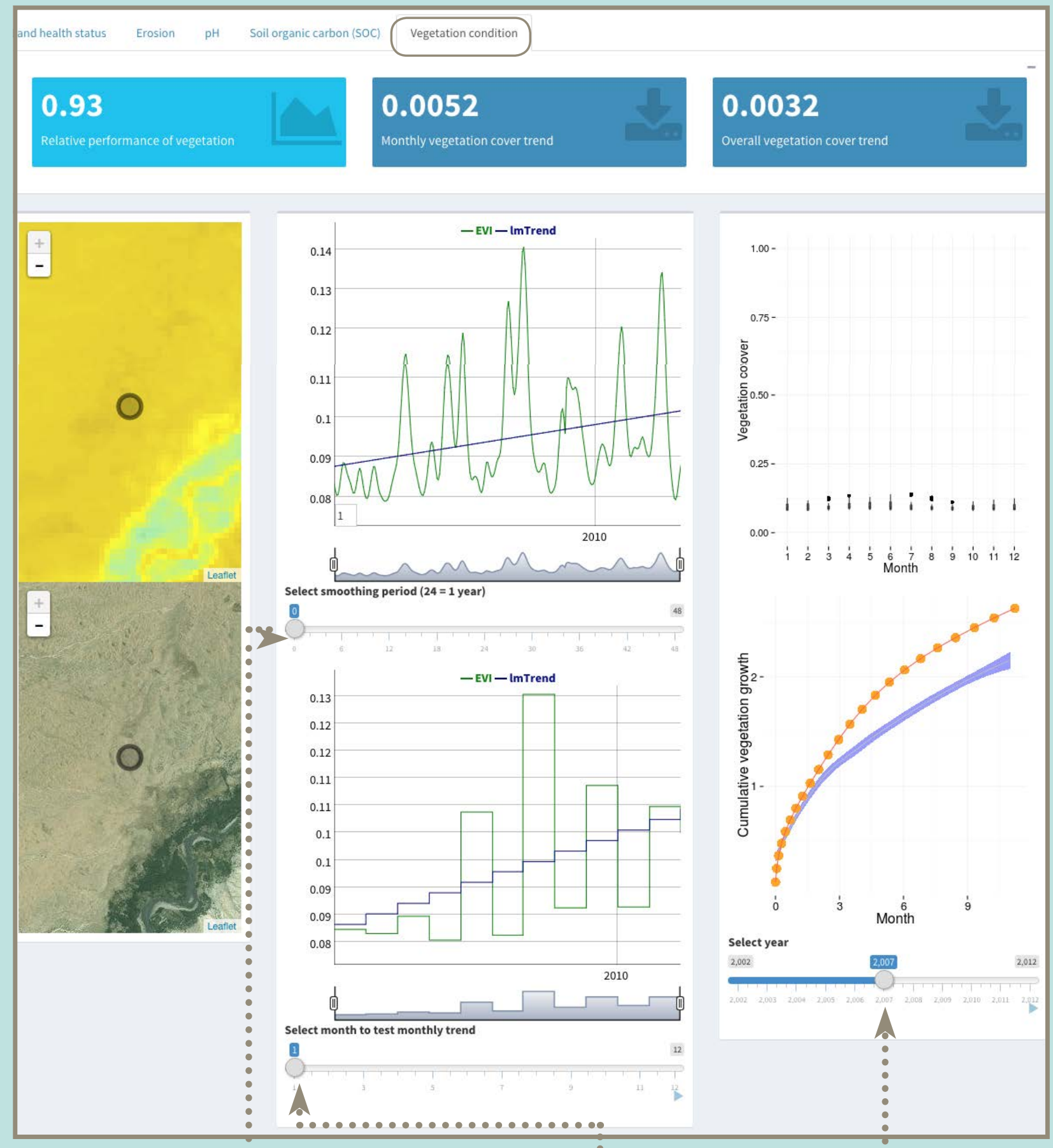

Slide to select smoothing period Slide to select month Slide to select year

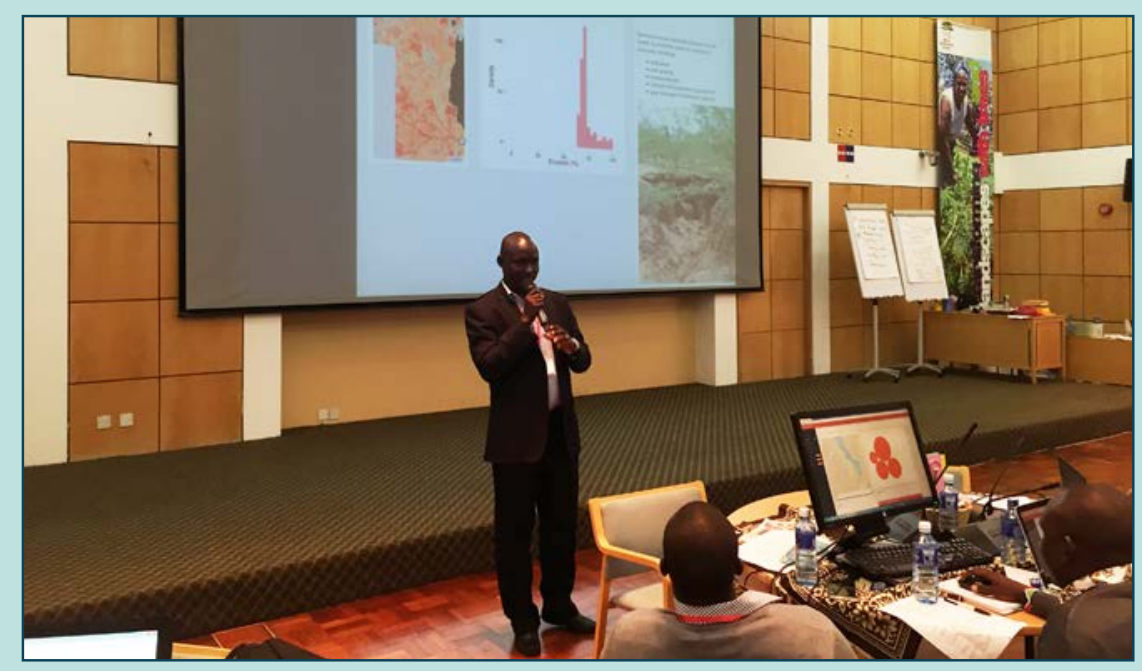

Turkana Government Sector feedback on Diagnostic Dashboard Facilitated by Philip Aemun UNICEF 


\section{ENERGY DASHBOARD}

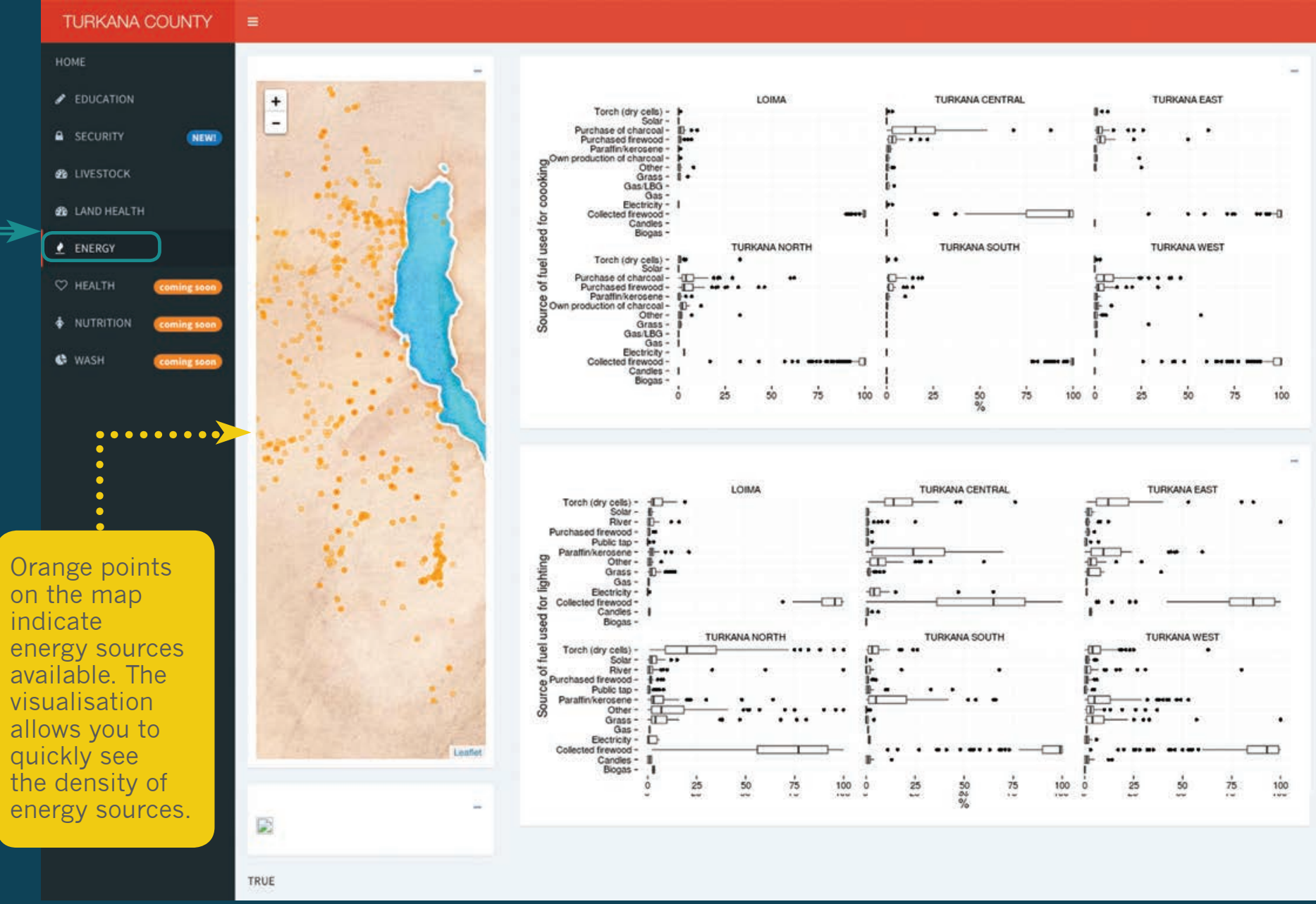

\section{DATA VISUALISATION FOR FUEL SOURCE USED FOR COOKING}

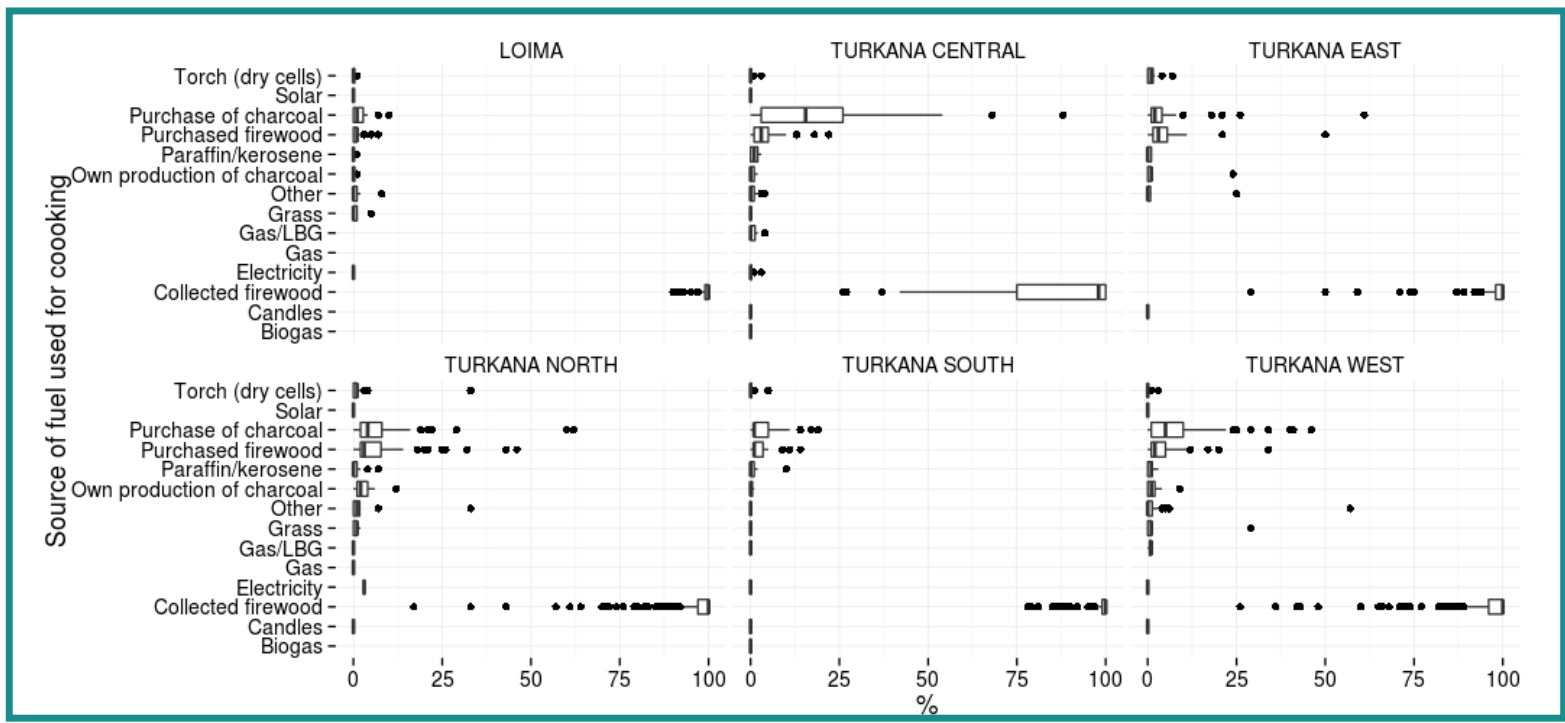

View the breakdown of various energy sources in various Turkana districts for COOKING PURPOSES. This graph will help identify the energy sources that is most prevelant to a specific area within Turkana County, and compare energy sources to other areas. 
DATA VISUALISATION FOR FUEL SOURCE USED FOR LIGHTING

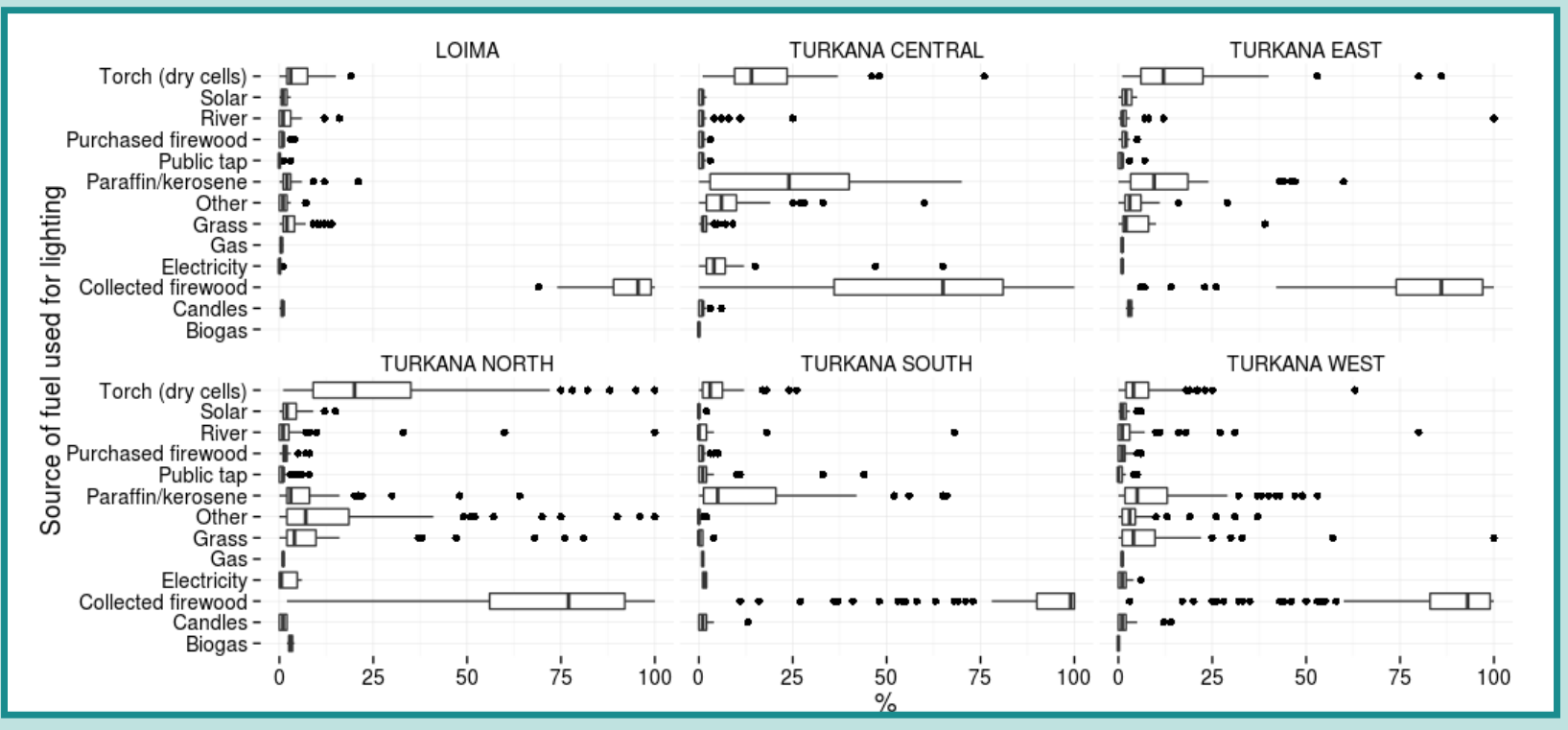

View the breakdown of various energy sources in various Turkana districts for LIGHTing PURPOSES. This graph will help identify the energy sources that is most prevelant to a specific area within Turkana County, and compare energy sources to other areas.

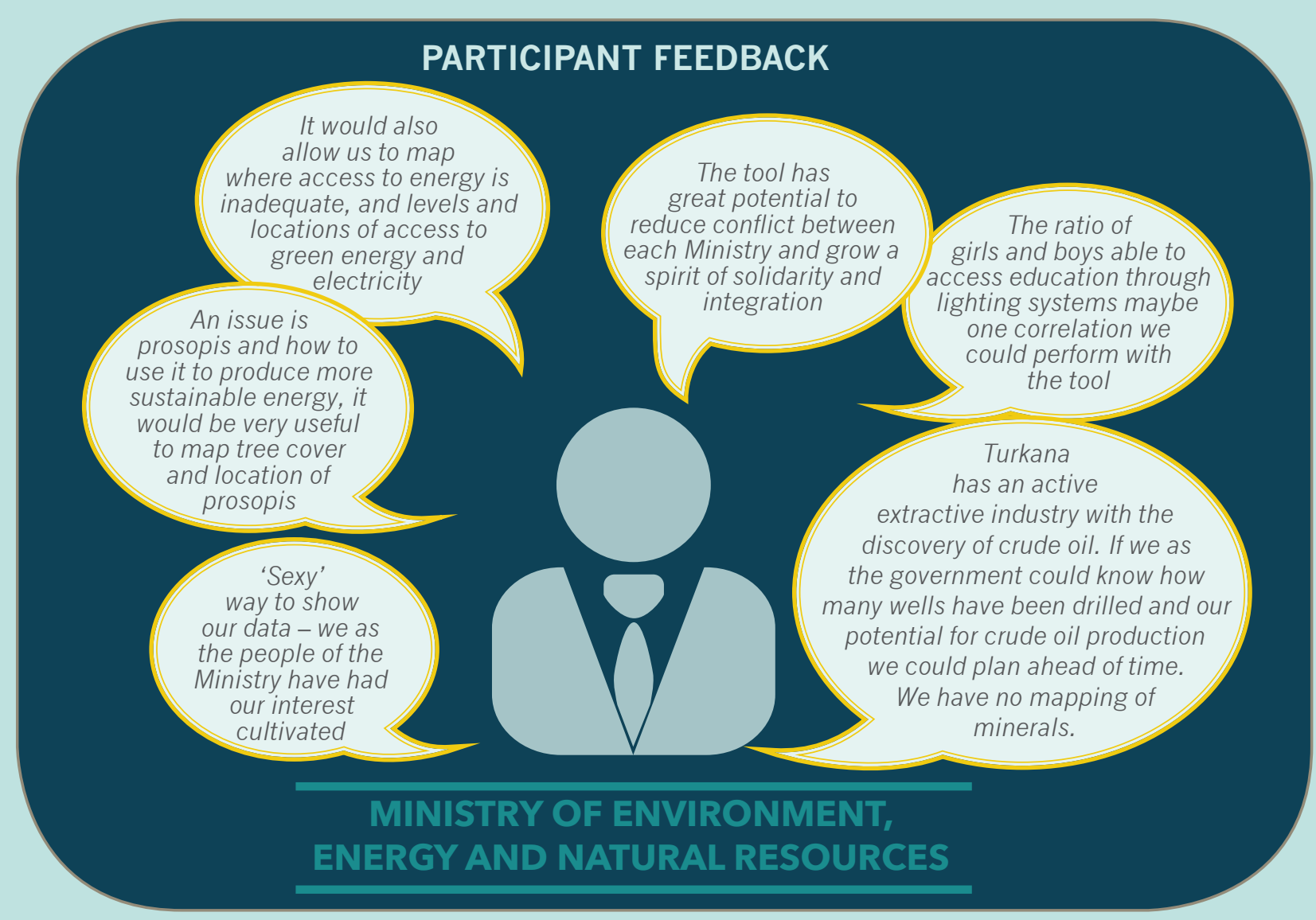




\section{IRRIGATION MODULE}

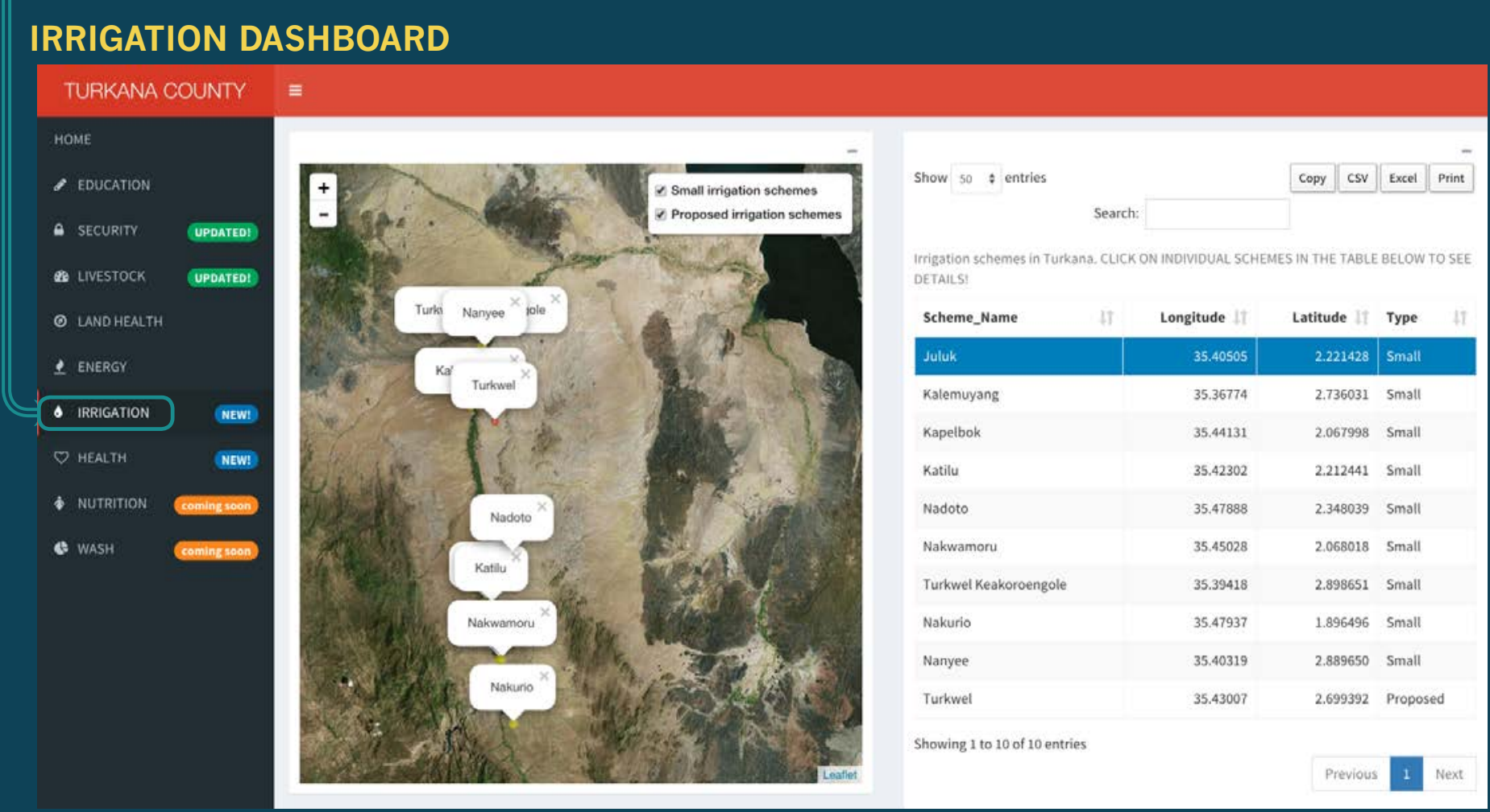

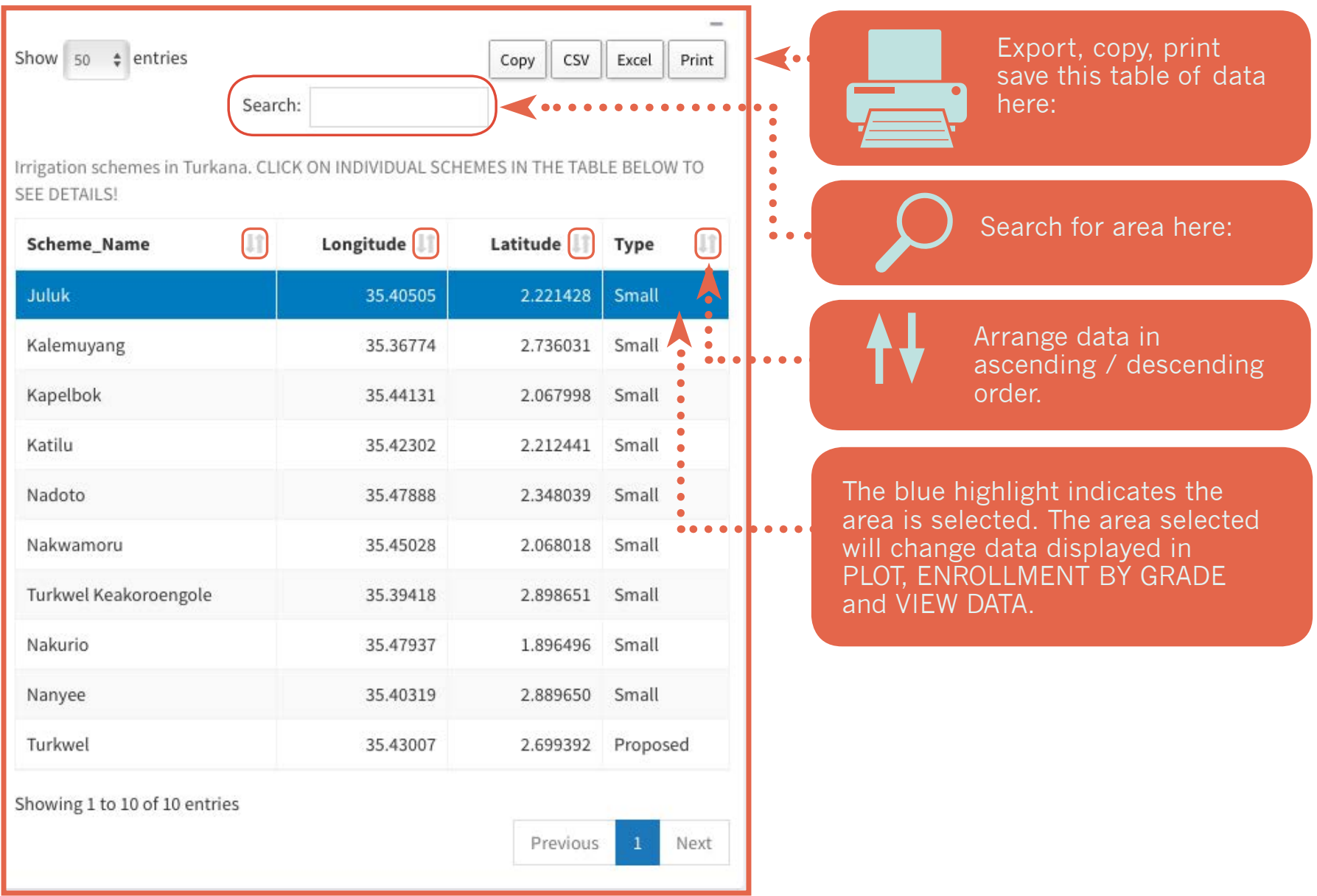


VIEW THE TURKANA COUNTY MAP WITHOUT THE SMALL IRRIGATION SCHEMES LABELS

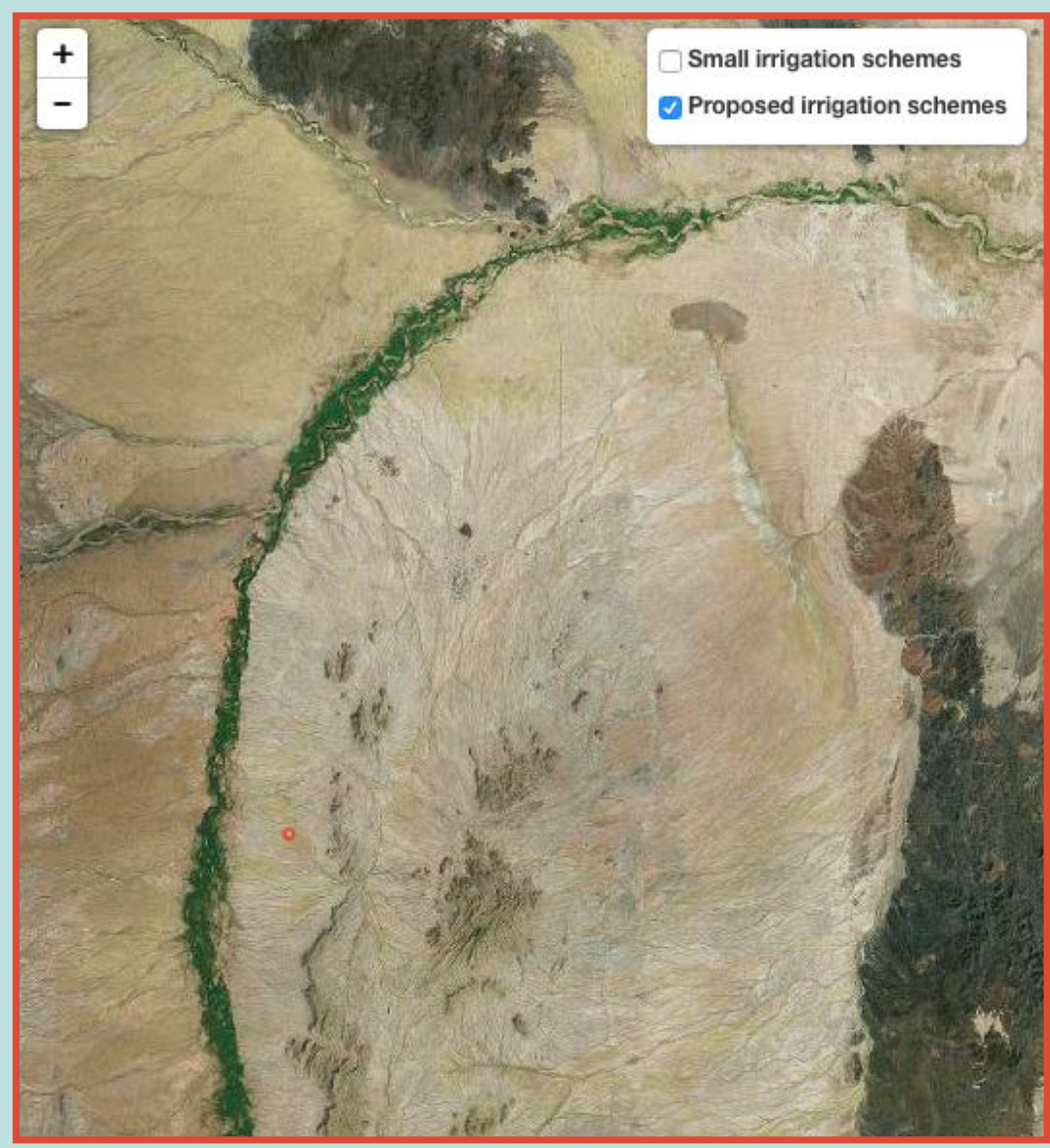

VIEW THE TURKANA COUNTY MAP WITH THE SMALL IRRIGATION SCHEMES LABELS

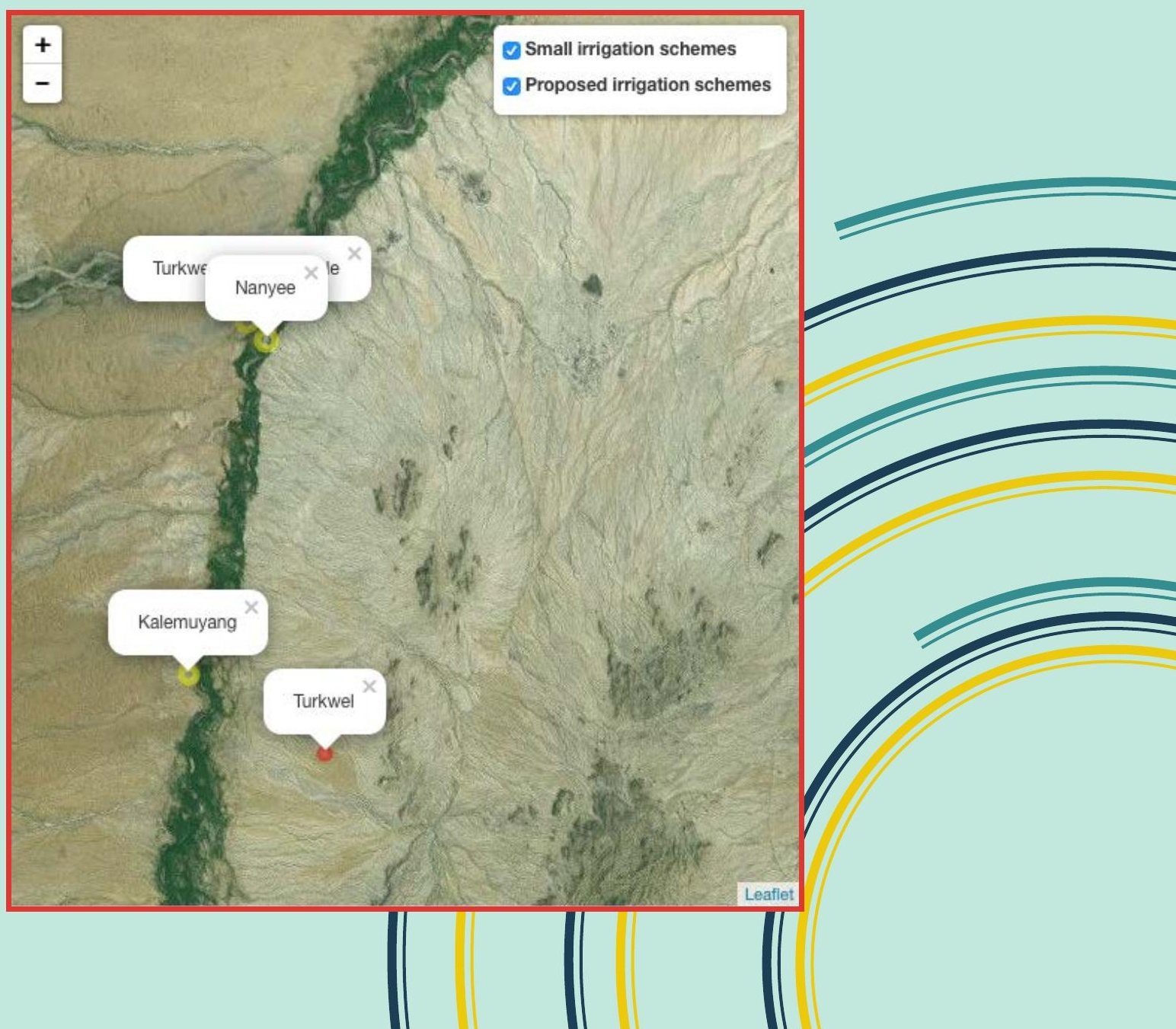




\section{HEALTH MODULE}

\section{HEALTH DASHBOARD}
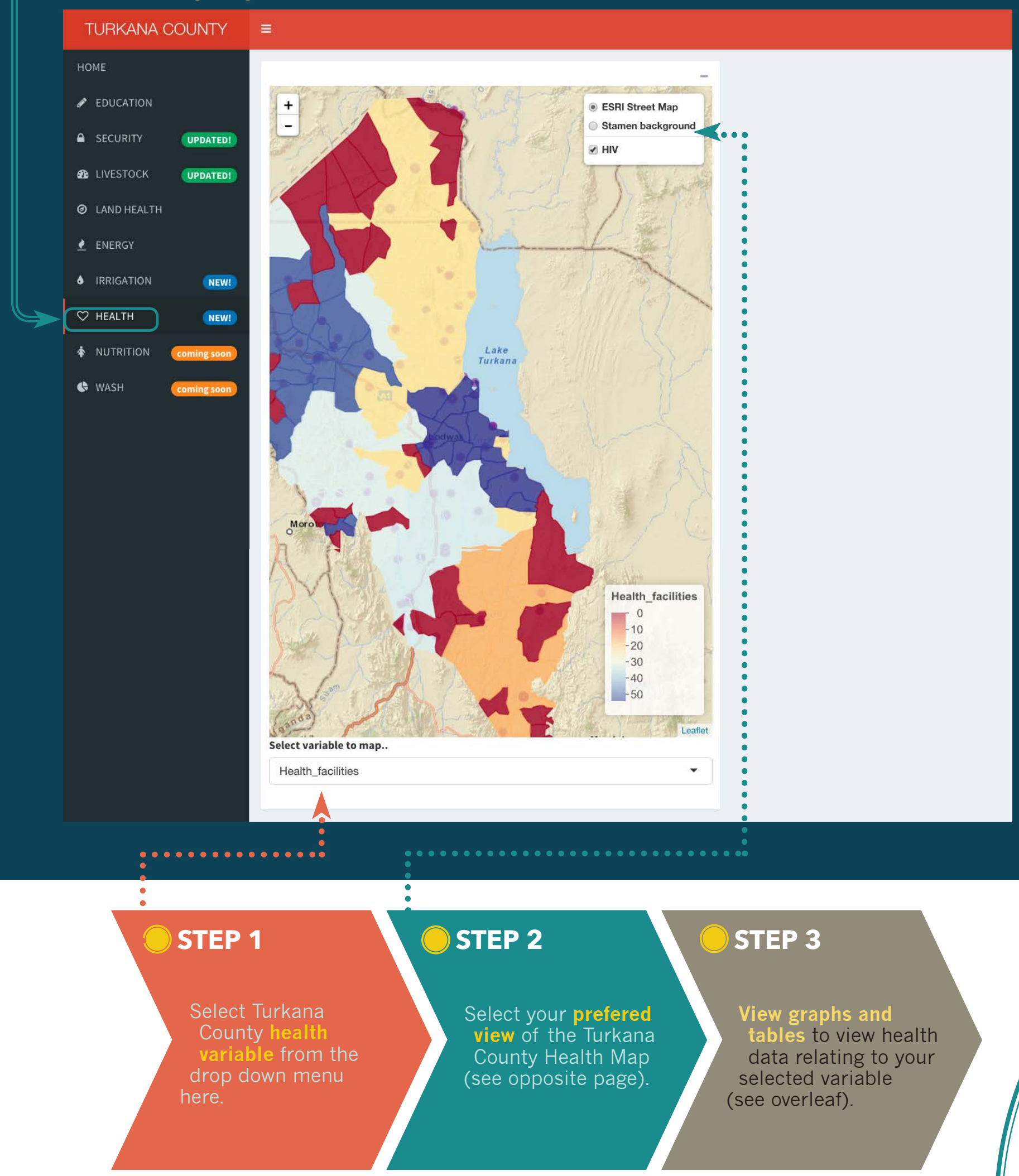


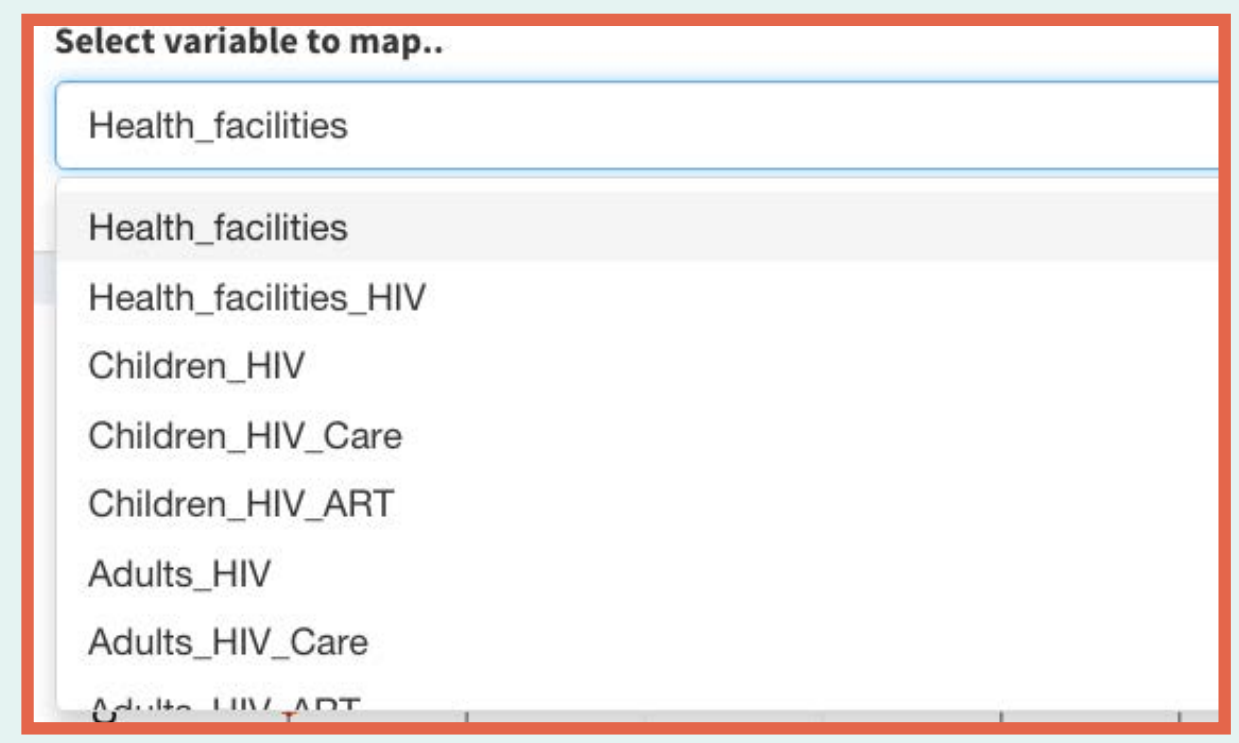

Variable for Map: Health facilities / Health facilities HIV / Children HIV / Children HIV Care / Children HIV ART / Adults HIV / Adults HIV Care / Adults HIV ART.

\section{VIEW THE TURKANA COUNTY HEALTH MAP WITH STAMEN BACKGROUND}

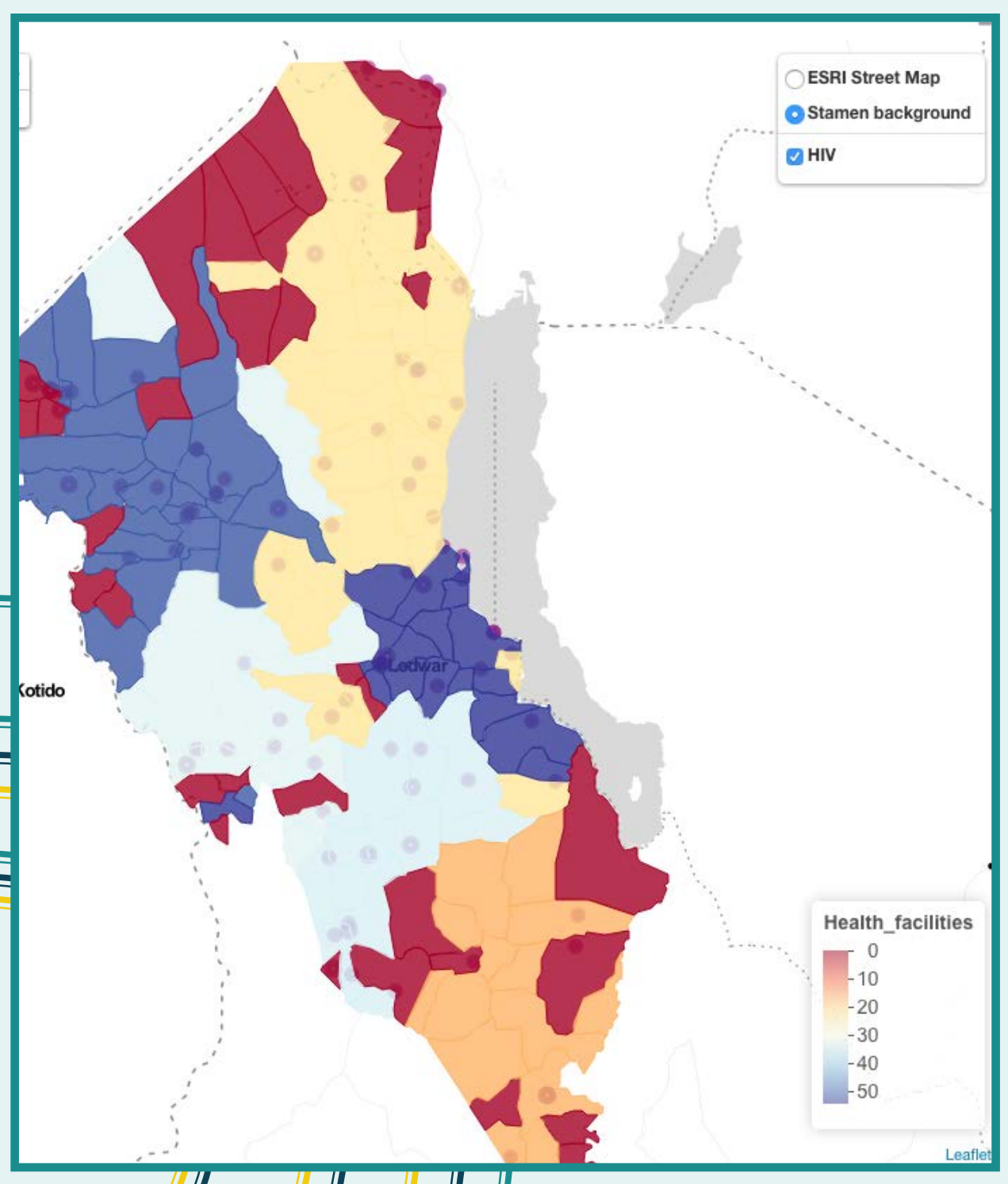




\section{VIEW THE DATA OF YOUR SELECTED VARIABLE RELEVANT TO CONSTITUENCY.}

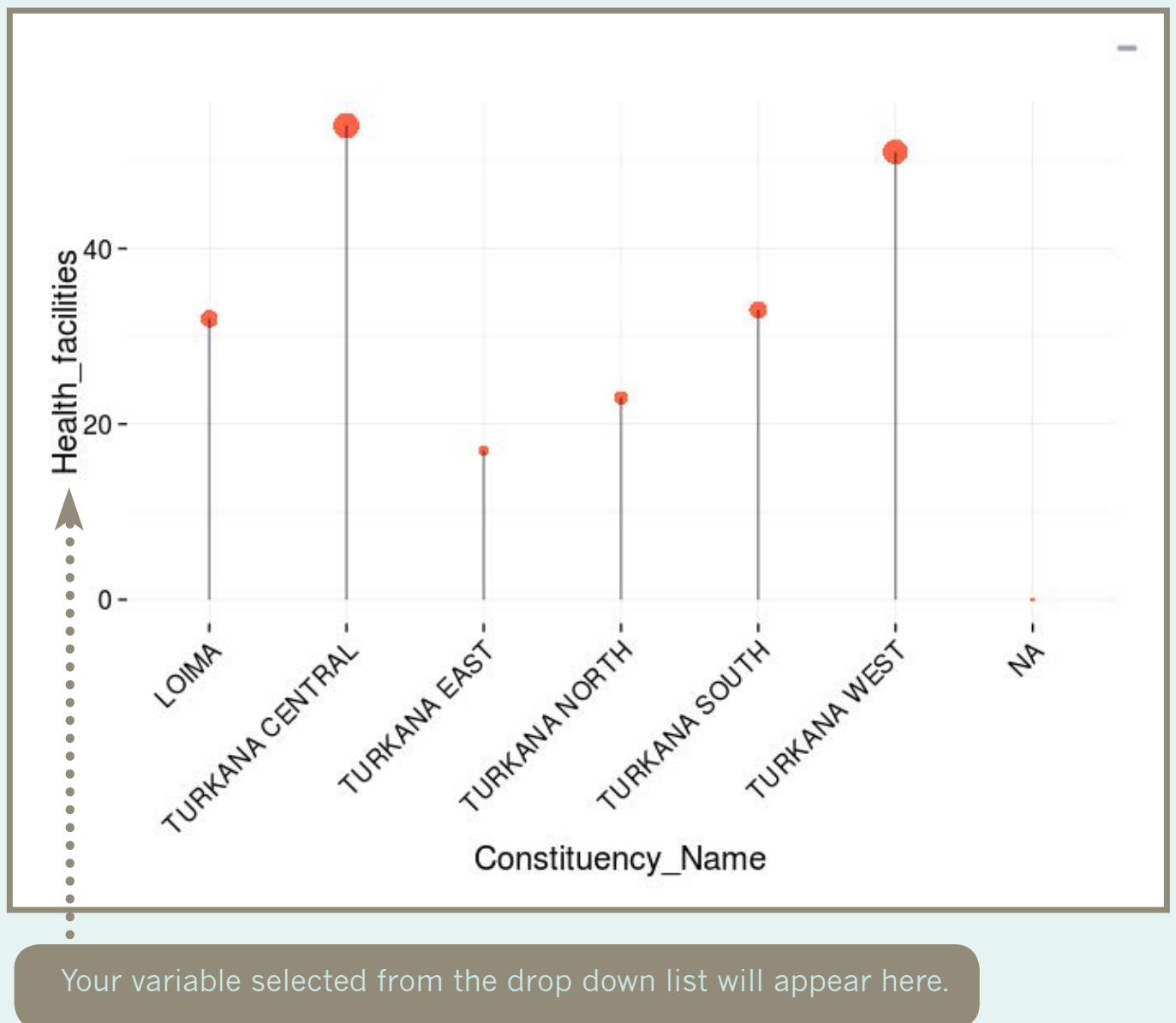

\section{VIEW DATA OF ALL VARIABLES IN TABLE FORMAT.}

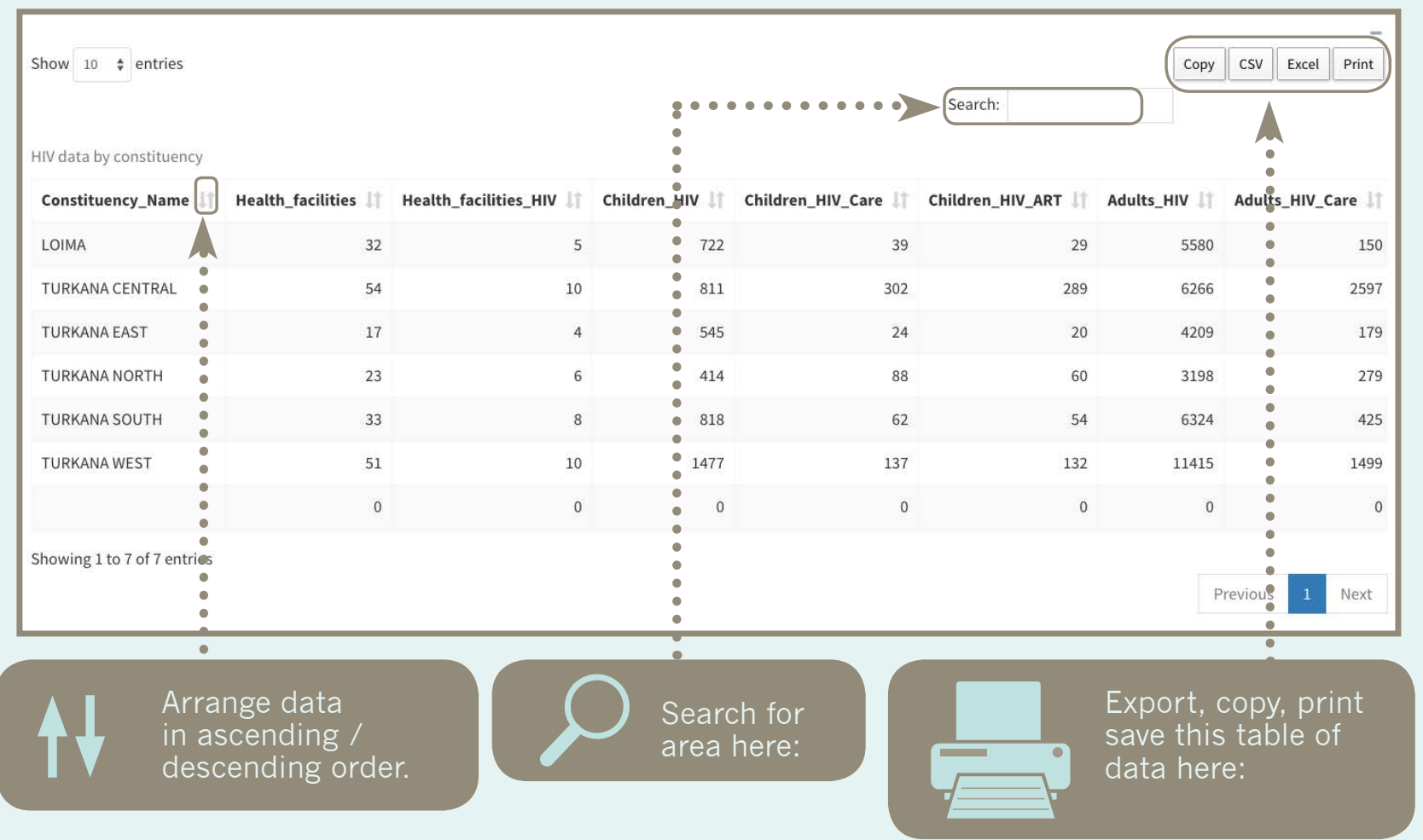




\section{WATER SANITATION AND}

\section{HYGIENE MODULE}

TURKANA COUNTY $\equiv$

\section{HOME}

- Education

a SECURITY

2. LIVESTOCK

UPDATED!

(a) LAND HEALTH

- energr

- IRRIGATION

$\bigcirc$ HEALTH

क NUTRITION

\& WASH
Show $50 \leqslant$ entries

Copy CSV Excel Print

Search:

UNICEF WASH

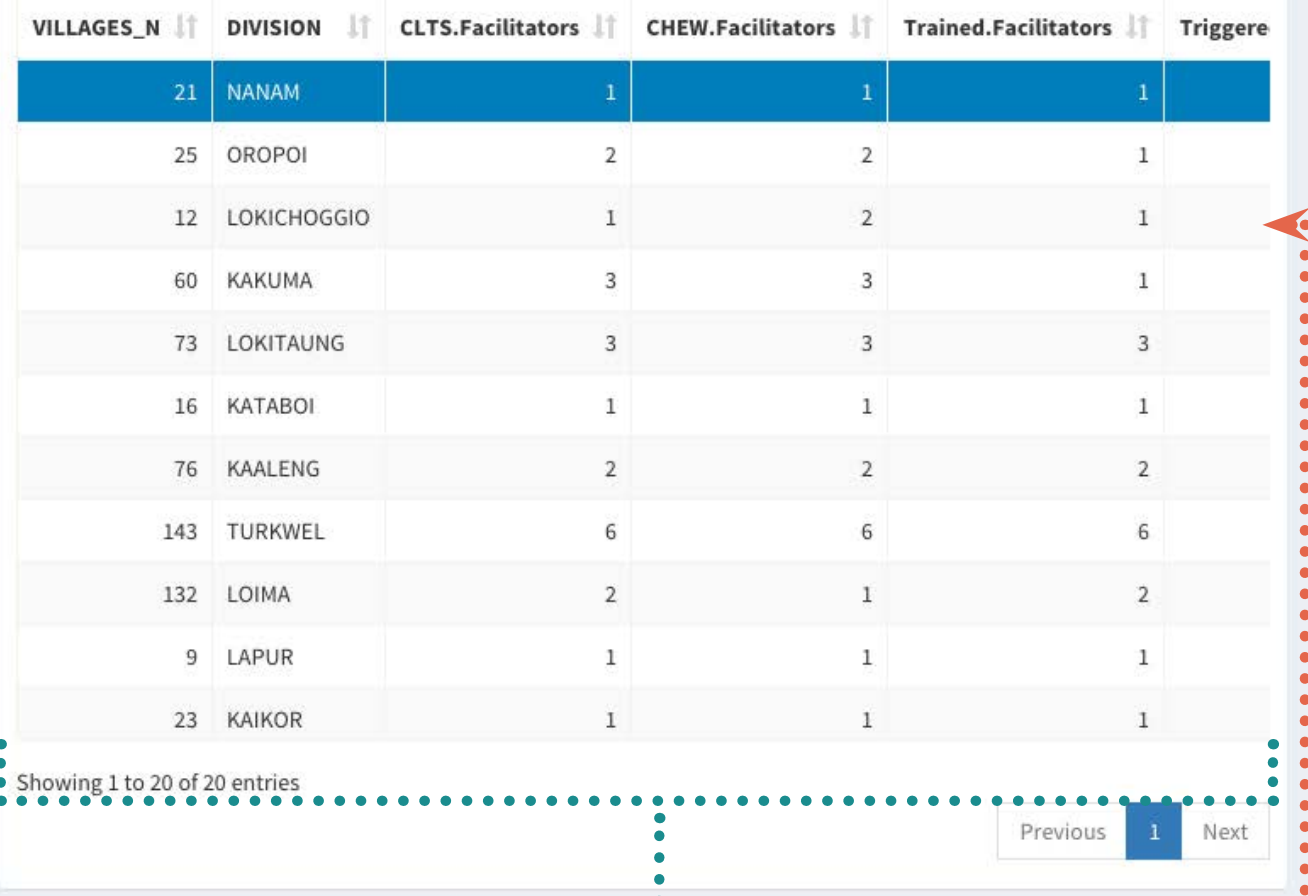

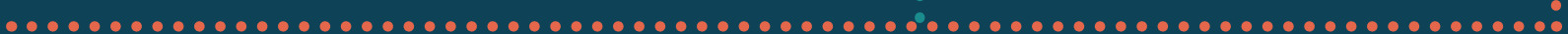

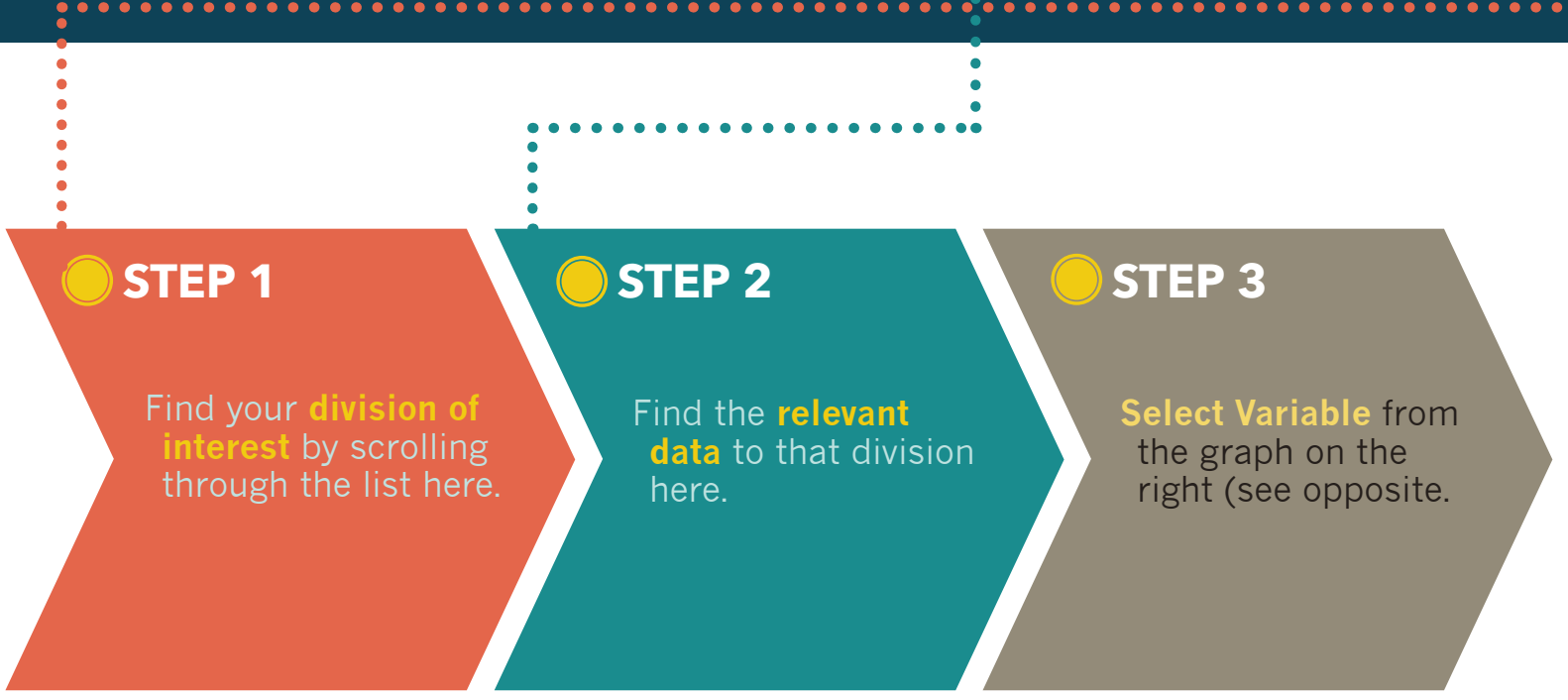




\begin{tabular}{l} 
Select variable \\
VILLAGES_N \\
\hline VILLAGES_N \\
CLTS.Facilitators \\
CHEW.Facilitators \\
Trained.Facilitators \\
Triggered \\
ODF.Claimed \\
DPHO.Verified \\
Cartifind
\end{tabular}

Variable for Division: VILLAGES_N/ CLTS. Facilitators / CHEW. Facilitators / Trained Facilitators / Triggered / ODF Claimed / DPHO Verified/ Certified
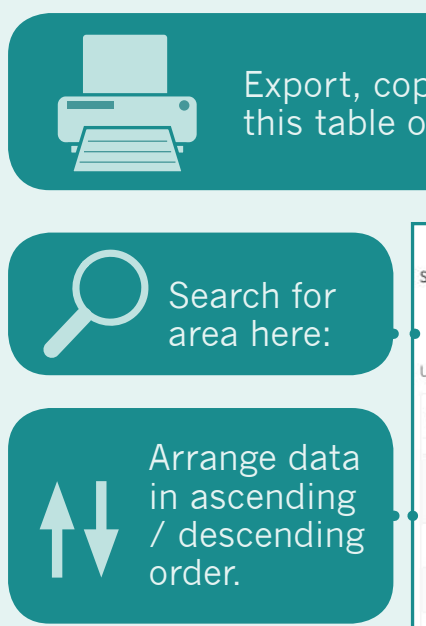

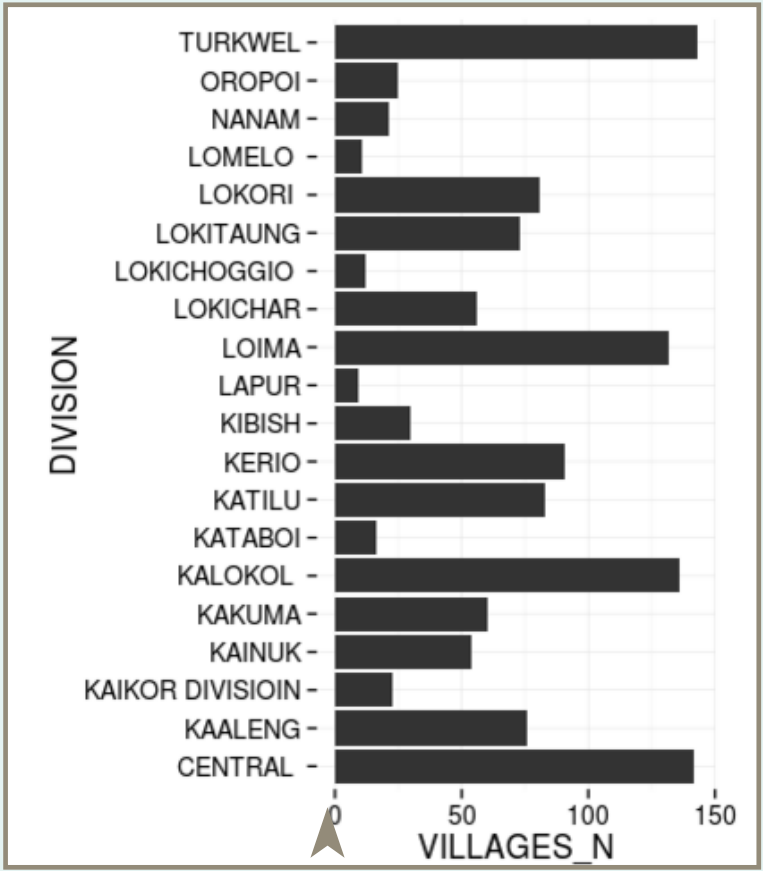

See the relevant data for your selected variable reflecteid in the gaph in relation to Turkana County Division

\section{(ㅇ) unicef

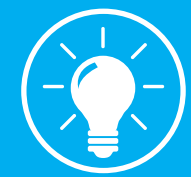 \\ WASH}

Inadequate and unsafe water, poor sanitation, and unsafe hygiene practices are the main causes of diarrhoea, and lead to 361,000 under-5 child deaths annually. Poor sanitation, water and hygiene have many other serious repercussions. Children - and particularly girls - are denied their right to education because their schools lack private and decent sanitation facilities. Women are forced to spend large parts of their day fetching water. In Kenya access to improved drinking water in 2015 is $63 \%$ but with marked disparities between rural and urban populations; many counties in the Arid and Semi-Arid Areas having significantly lower access than the national average. The sanitation situation is considerably worse with just $30 \%$ of the population having access to improved sanitation, and with limited progress made during the MDG era[i]. However, following the introduction of the new constitution has established the right of all citizens to sanitation and safe water and set a target of universal access by 2030 . The process of devolution provides an exciting opportunity to address many of the sector challenges by bringing decision-making closer to the users. UNICEF has played a key role in supporting counties through the development of micro plans for Community Led Total Sanitation, which facilitate the incorporation of equity analysis into planning and realization of targets. UNICEF has also been working closely with county governments to develop models for sustainable rural drinking water supply services, and making the case for increased budget allocation towards operation and maintenance costs. (http:// www.unicef.org/wash/)

[1] WHO/UNICEF Progress on Sanitation and Drinking Water - 2015 Update and MDG Assessment 


\section{NUTRITION MODULE}

TURKANA COUNTY झ

HOME

- education Updated!

- SECURITY

2 LIVESTOCK

UPDATED!

(๑) LAND HEALTH

1 ENERGY

- irRigation

$\bigcirc$ HEALTH

- nutrition

E WASH

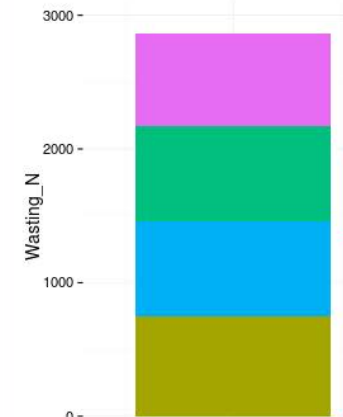

2011

BETA!

Select variable to map: Wasting_N

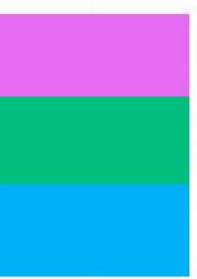

2012
Year

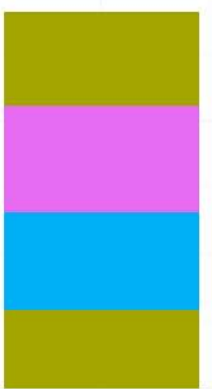

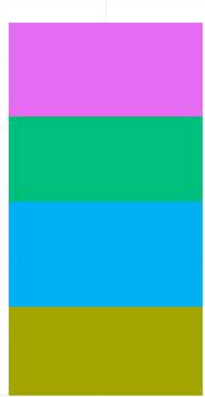

2014

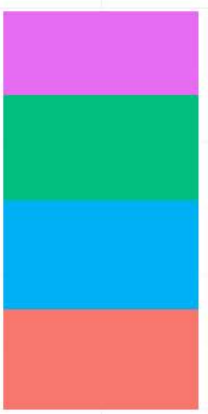

2015

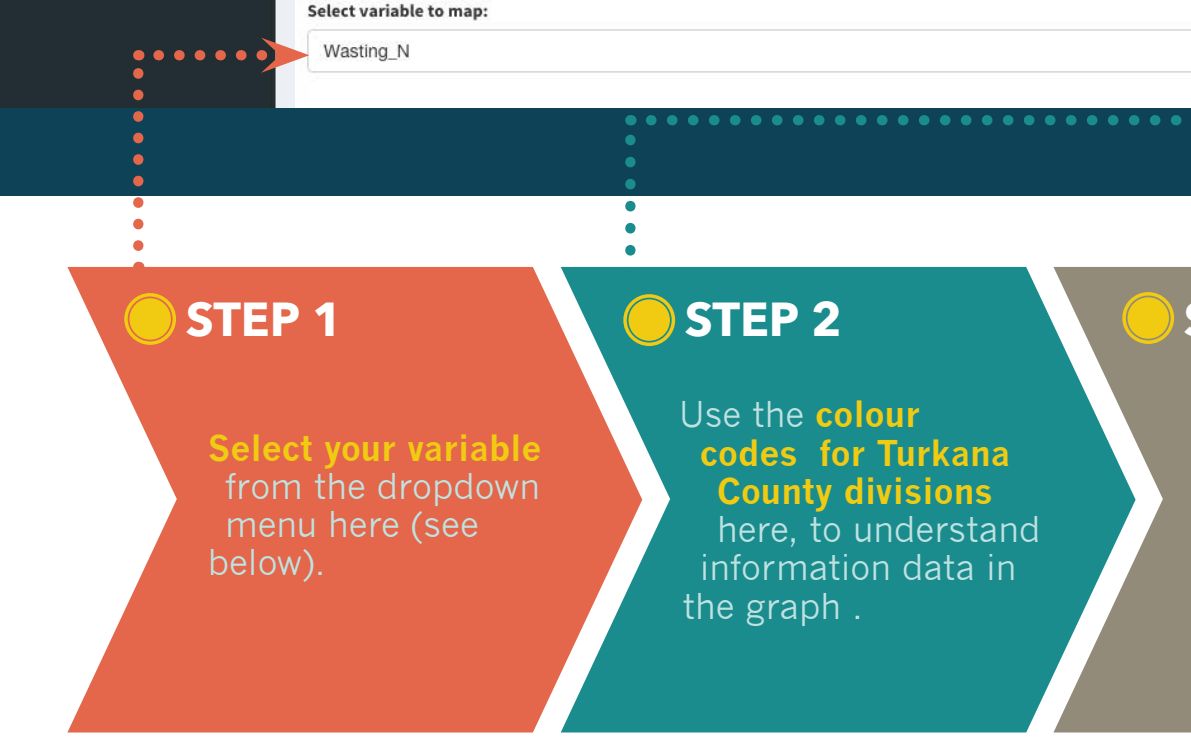

STEP 3

Select variable to map:

Wasting_N

Wasting_N

GAM_mean

GAM_lower

GAM_upper

SAM_mean

SAM_lower

SAM_upper

Variable to map: Wasting_N / GAM_mean / GAM_lower / GAM_upper / SAM_ mean / SAM_lower/SAM_upper/Stunting_M 


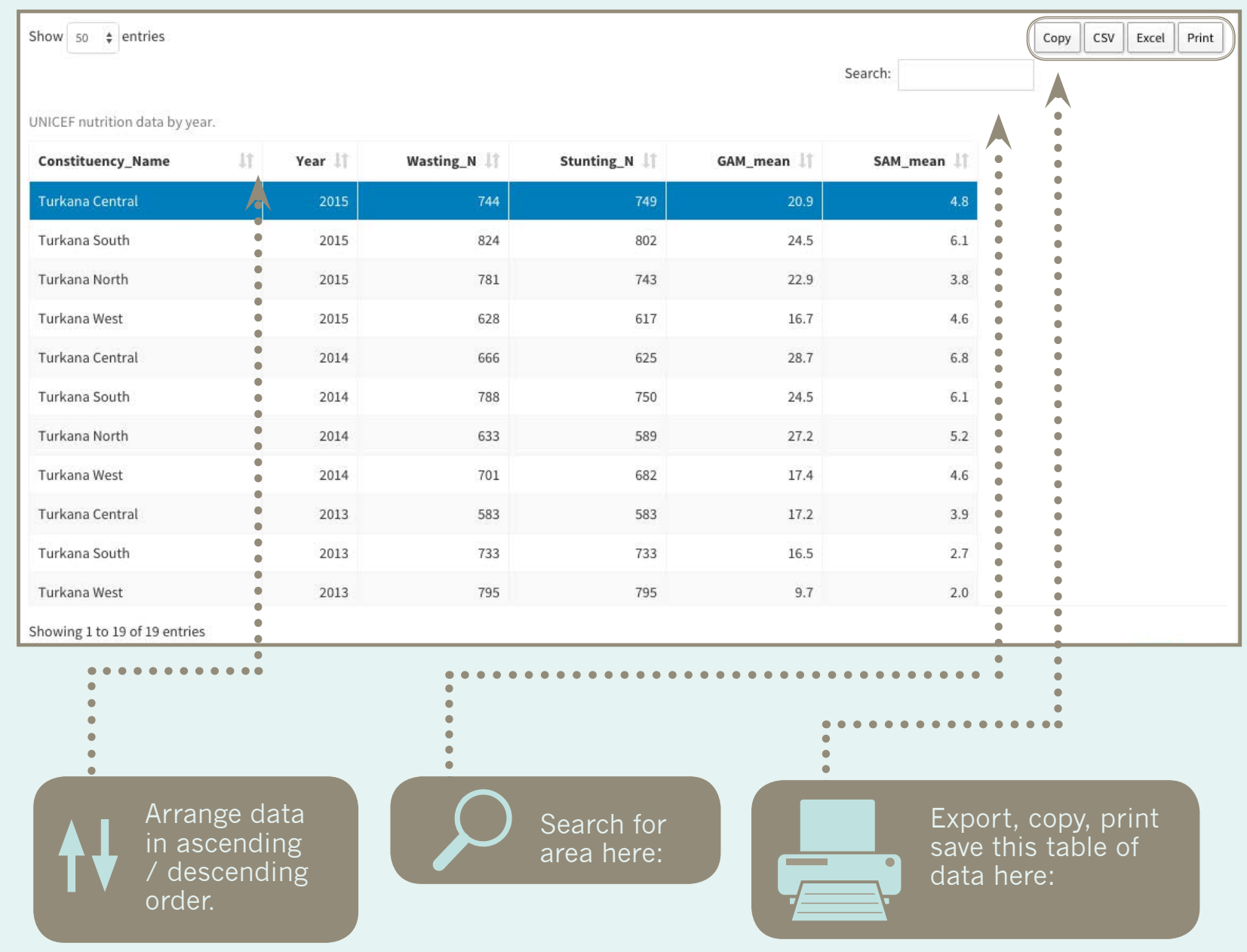

\section{NUTRITION}

Proper nutrition is every child's right: wellnourished children are generally healthier, more active, learn better in school and have a greater chance of fulfilling their potential. The nutrition sector in Kenya has realised key achievements especially in terms of improved nutrition indicators in recent years with data from the most recent Kenya Demographic Health Survey (KDHS) 2014 indicate an overall improvement in the nutritional status of children in Kenya over the last 5 years[1]. Between 2008 and 2014, stunting has decreased from $35 \%$ to $26 \%$, wasting from $7 \%$ to $4 \%$, and the proportion of underweight children declined from $16 \%$ to $11 \%$ as shown in the graph below. Kenya has also attained the Millennium Development Goal, 2015 target for proportion of underweight children which stands at $11 \%$. The $2014 \mathrm{KDHS}$ has shown a significant increase in exclusive breastfeeding rates for children up to 6 months from $32 \%$ in 2008 to $61 \%$ in 2014 . According to the latest Global Nutrition Report 2015, out of the 74 countries for which data exist, Kenya is the only country that is on course to meet all five of the World Health Assembly maternal and child nutrition targets. This is based on the improved rates of exclusive breastfeeding, declining rates of stunting, wasting, underweight, and overweight and anemia in women 15.49 years. This breadth of performance is good news. However alot more needs to be done as the national levels figures mask the large inequities across the country, most noted in the arid and semi-arid lands where nutrition and health outcomes for children are far below the national average. Efforts are ongoing at national and county levels led by the $\mathrm{MoH}$ and supported by the UN, Development Partner and CSO, which focus on creating an enabling policy environment for good nutrition; scaling up evidence based nutrition specific interventions at community and facility level; strengthening coordination within and outside the nutrition sector; increasing collaboration with Agriculture, Health, Livestock, Education WASH and Trade; increasing responsiveness to crisis, supporting enhanced supply chain management and monitoring of the nutrition situation and subsequent programme response 


\section{MOVING FORWARD WITH}

\section{THE TOOL}

RESILIENCE DIAGNOSTIC

\& DECISION SUPPORT TOOL .

DATA SOURCES IDENTIFIED TO INPUT INTO THE TOOL

AT THE WORKSHOP

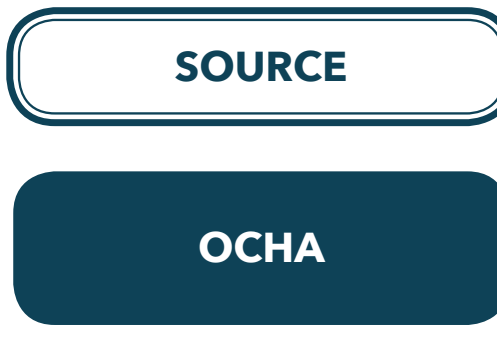

DEVELOPMENT PARTNER MAPPING

\section{POPULATION DATA}

OXFAM

IEBC

NDMA

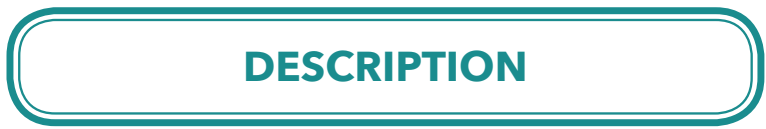

Investment mapping tool for ASALs

ASAL Stakeholder forum

Sex, age, cohorts

Water points data

County \& sub-counties admin and political

Head teachers update on enrollment and dropouts and transition

Long and short rains assessment

\section{Security Directorate}

TURKANA COUNTY INCIDENCE DATA 


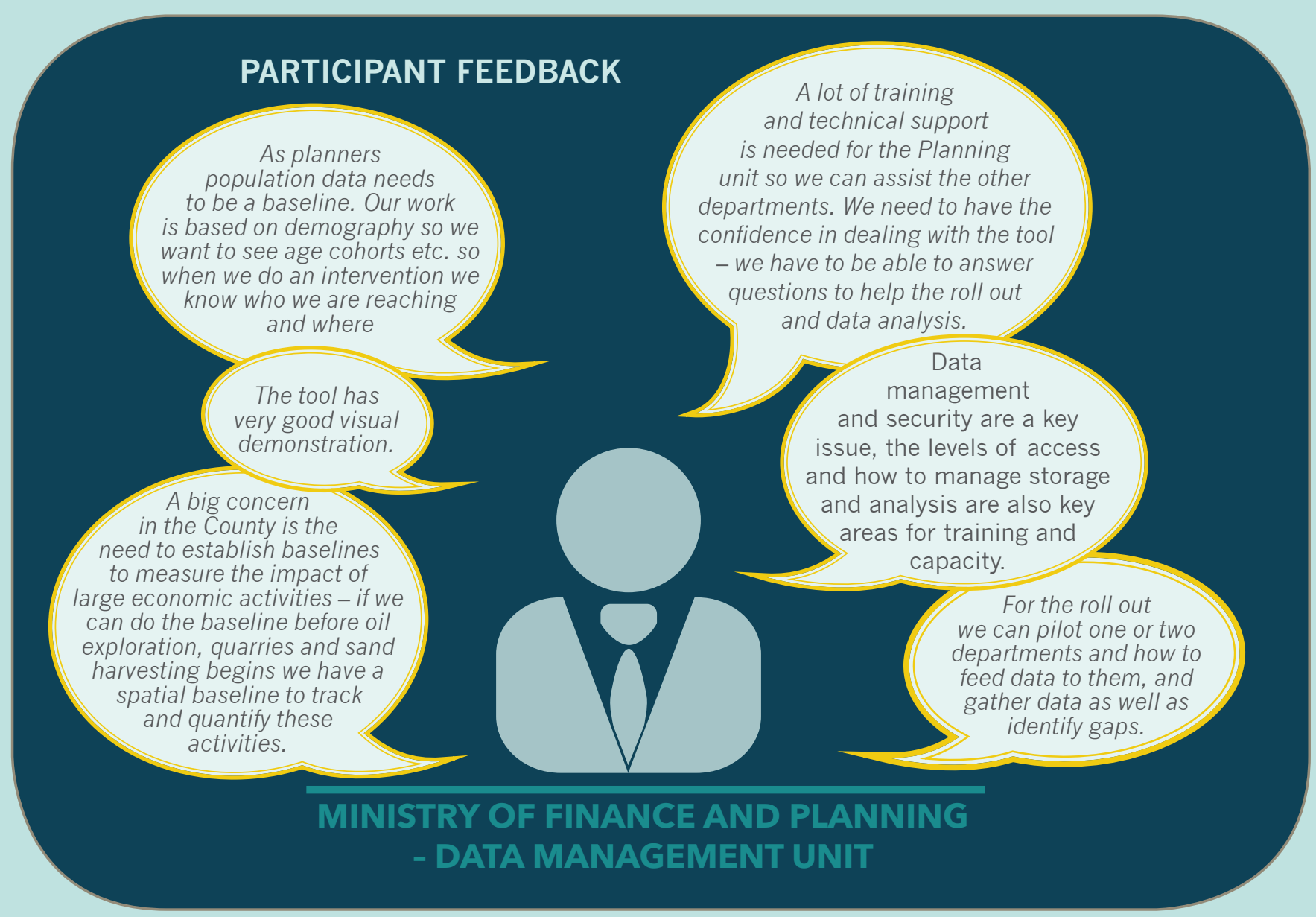

SUGGESTIONS FOR ADDITIONAL MODULES
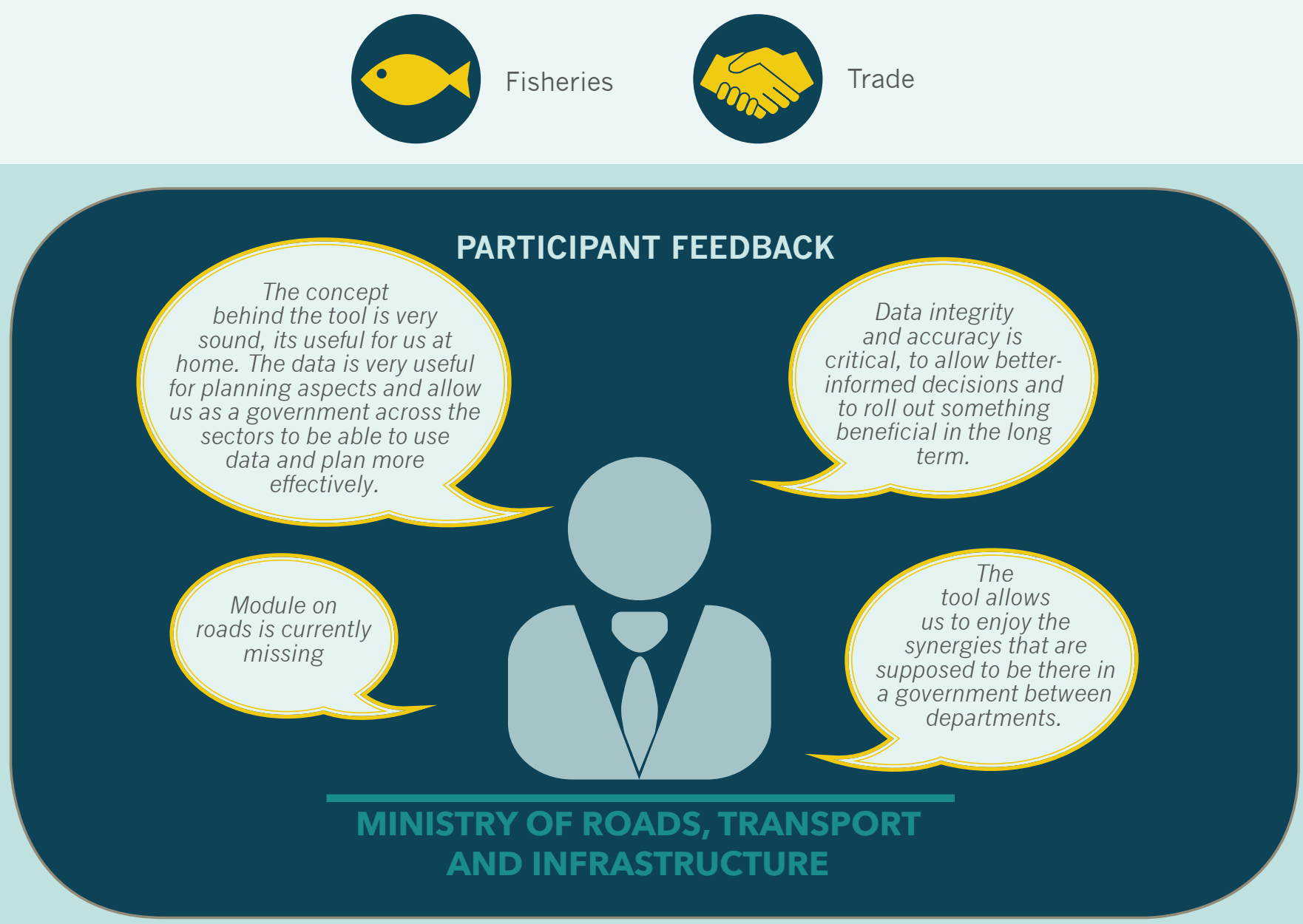


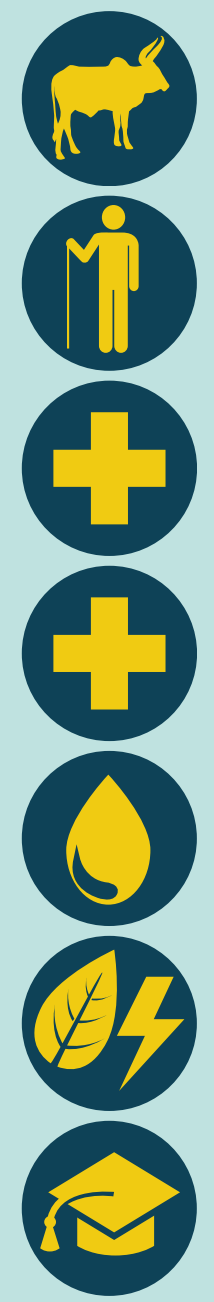

Incidence of cattle rustling

Pastoralist migratory patterns; where are the kraals and where do they settle per season

Sanitation coverage and rates of ODF

Number of latrines available

Precipitation predictions

Public institutions e.g. schools able to access solar and green energy

In the education module - enrollment and retention - this would be very powerful to show a governor there is a drop in enrollment and tie it to a shock like a drought by tying it back to the Land Health Module

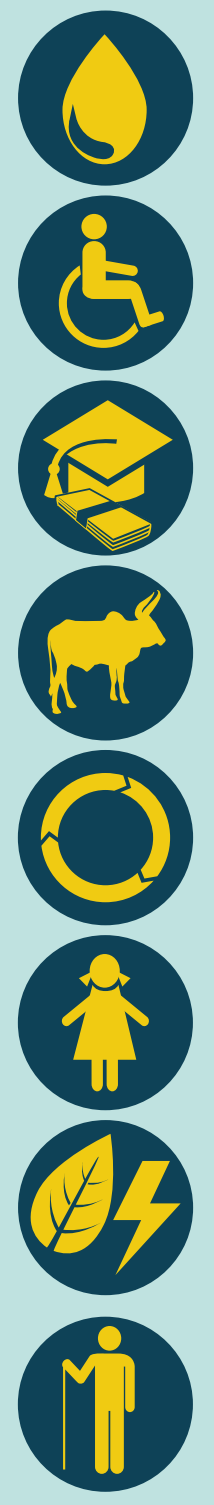

Seasonal rainfall and malnutritio

Children with disabilities

School bursaries

Livestock

Economic extraction activities (quarry, sand harvesting, oil exploration)

Number of ECDs and location

Access to green energy

Migratory patterns of pastoralists

\section{The dream is} to have Turkana as one of the model counties. We are moving to that direction, as a County government we are engaging with many partners, for example a UN partnership on performance management and revenue collection gaps.

If a trade module could be added to the tool it would be very useful, so we can visualize trade volume, livestock sales, milk production etc., and have access to a monthly figure. government has, doesn't y

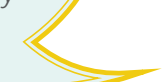

ECONOMIC ADVISOR TO THE GOVERNOR

\section{The tool is so} informative and its just the beginning, we can put data, we can correct data and various areas, Turkana has a map that the national show the extreme end

$<$
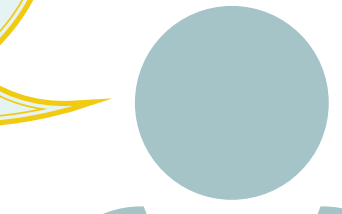
of Turkana.

will share with

the Governor and show

him how to move with the map which is very interactive

'be assured you have an agent here'

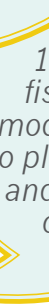

\section{There is a} $12 \%$ dependence on fisheries by Turkana, a module on this to allow us to plan ahead for 100 years and ensure sustainability of the lake would be great. 


\section{REFLECTIONS FROM STAKEHOLDERS FROM EVIDENCE INTO DECIONS MAKING WORKSHOP AUGUST 18 - 20 2015, ICRAF, NAIROBI}

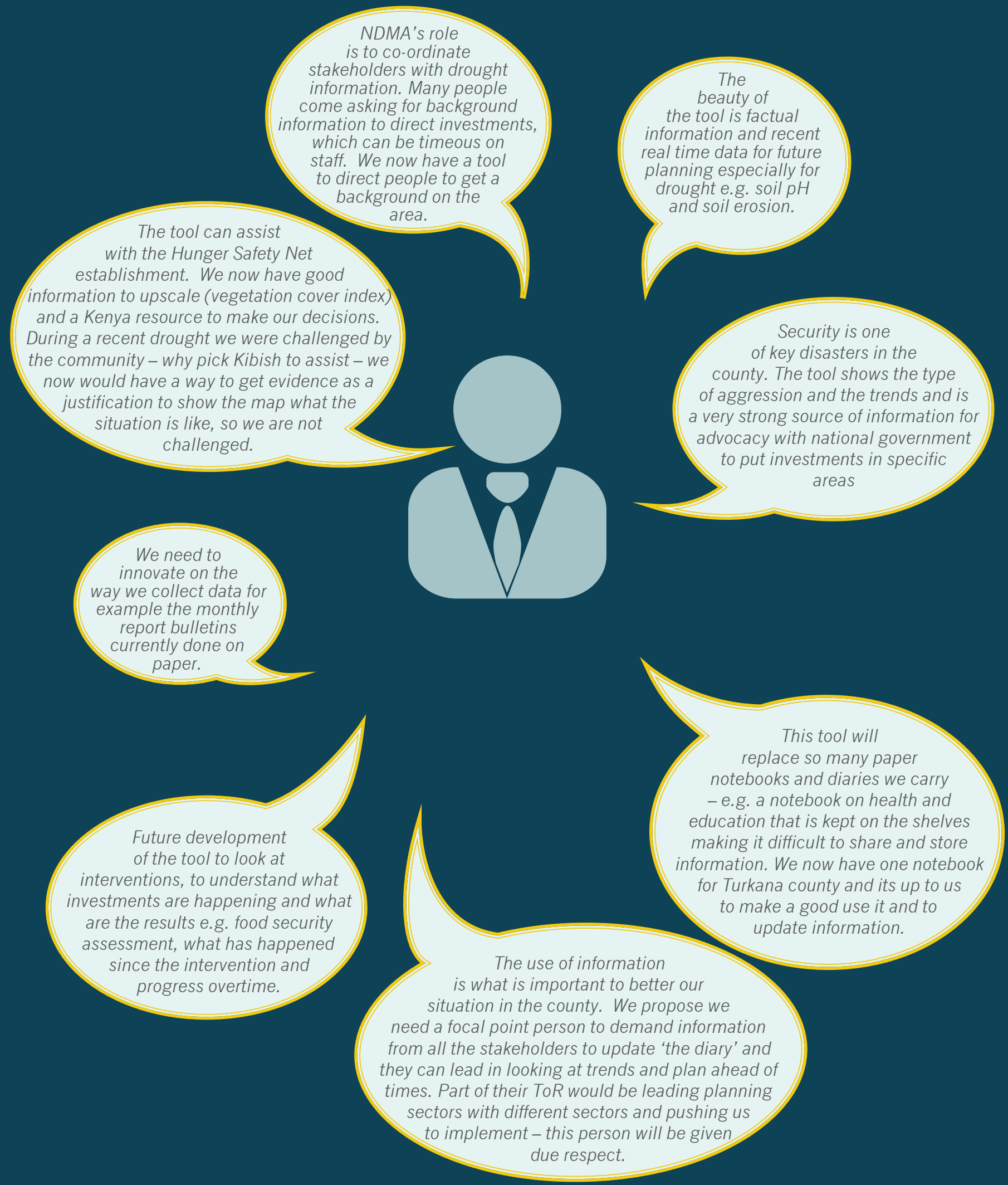


FUTURE IDEAS FOR THE DASHBOARD AND ADDITIONAL FEEDBACK

Technical ward - water and agriculture for mobile information (could be other themes / sectors)

Farm census

Issue of synergy of planning and seeing the effects of that - significant different dimension to the tool

to develop in a second phase. To help understand and explore the expected results of the investment and importantly integration and inter-departmental investments and their impact on the landscape

Being able to print and export a summary of working session

Change the data displays as some of the scatter plots are too complicated to interpret and other options such as a histogram would be easier

Integrate with the NDMA Management Information System for comprehensive and accurate for data collection

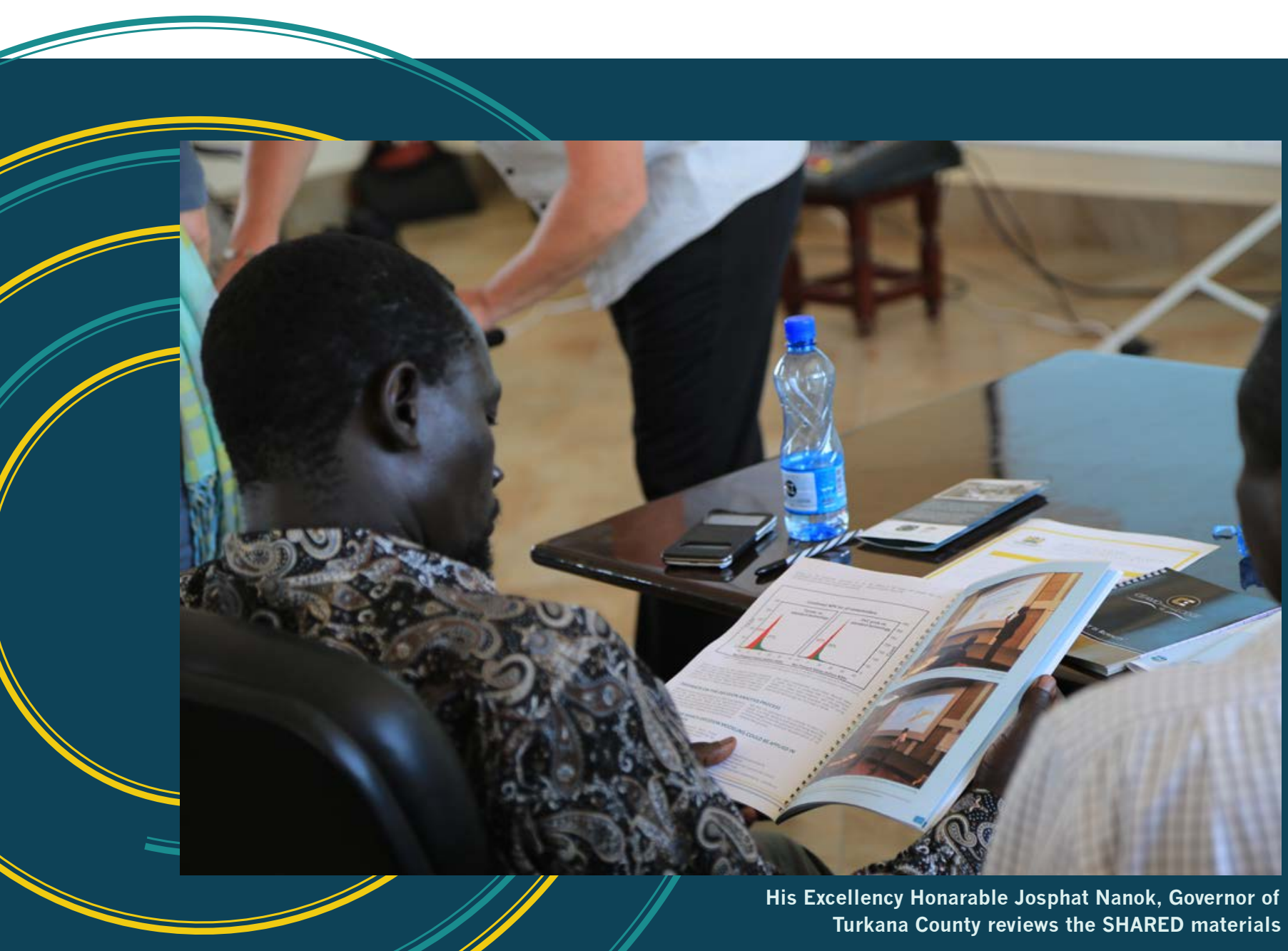




\section{PARTICIPANT FEEDBACK}

The support we are already witnessing, thank you to the team for the energy and knowledge and the kind of organization that has been put into the too.

Yes this will be our baby - so be it!

We need to prepare ourselves and engage in evidence-based information.

During the last Budget estimate review it took a lot of time to convince the committee on allocations as we did not have facts or data and we just based argument on supply. If we had data it would have been the correct way to make the decision.

\section{The}

Health Ministry

needs to think of the linkages with the Health MIS, to understand where future investments are needed and where surveillance is required.

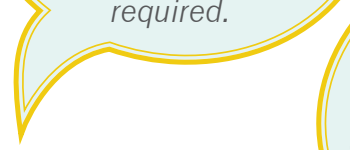
and Development Plan (ADP) needs to be informed by the tool. We will organize and fund a two-week workshop for users in making those decisions. Then further the tool can assist with the County budget and outlook paper.

The budget circular is start of the budget cycle and preparation for the Annua
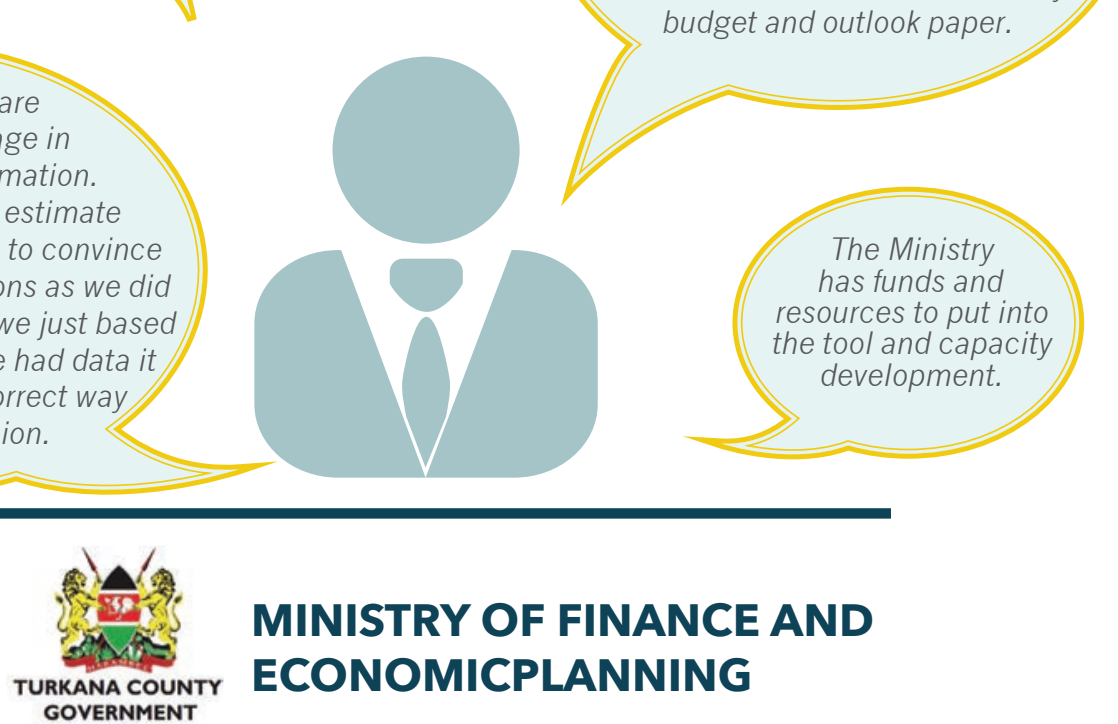

The Ministry has

been grappling with budget ceilings. If these can be factual by using evidence based arguments to the budget and appropriation committee this is a good way to make this presentation to put out argument across and the key priorities we need to achieve. This is our tool!

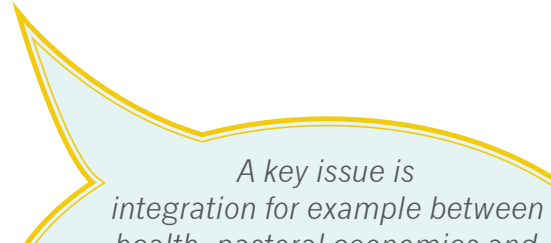

health, pastoral economies and education, instead of criticizing why there is less investment into pastoral economies in comparison to the education and health sectors the evidence needs to show us how

they are integrated. This is the type of discussion we need to have. 


\section{SHAREDO}

The Stakeholder Approach to Risk Informed and Evidence Based Decision Making 


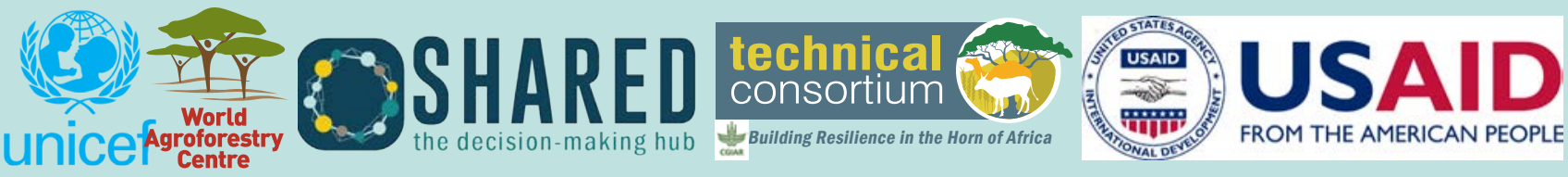

